\title{
Progress Letter Report on
} Bending Fatigue Test System Development for Spent Nuclear Fuel Vibration Integrity Study (Out-of-cell fatigue testing development - Task 2.4)

July 2013

Prepared by

Jy-An John Wang ${ }^{1}$, Hong Wang ${ }^{1}$, Thomas Cox ${ }^{1}$, Chuck Baldwin ${ }^{2}$

${ }^{1}$ Materials Science and Technology Division

${ }^{2}$ Fuel Cycle and Isotopes Division

Bruce B. Bevard

Project Manager

Reactor \& Nuclear Systems Division

Oak Ridge National Laboratory 


\section{DOCUMENT AVAILABILITY}

Reports produced after January 1, 1996, are generally available free via the U.S. Department of Energy (DOE) Information Bridge.

Web site http://www.osti.gov/bridge

Reports produced before January 1, 1996, may be purchased by members of the public from the following source.

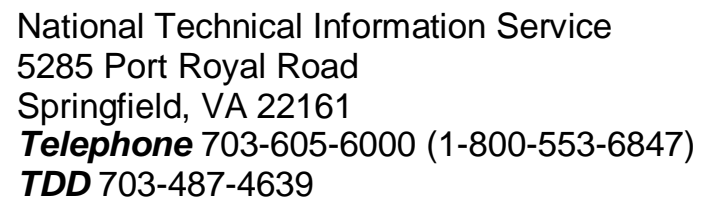

Reports are available to DOE employees, DOE contractors, Energy Technology Data Exchange (ETDE) representatives, and International Nuclear Information System (INIS) representatives from the following source.

Office of Scientific and Technical Information

P.O. Box 62

Oak Ridge, TN 37831

Telephone 865-576-8401

Fax 865-576-5728

E-mail reports@adonis.osti.gov

Web site http://www.osti.gov/contact.html

This report was prepared as an account of work sponsored by an agency of the United States Government. Neither the United States government nor any agency thereof, nor any of their employees, makes any warranty, express or implied, or assumes any legal liability or responsibility for the accuracy, completeness, or usefulness of any information, apparatus, product, or process disclosed, or represents that its use would not infringe privately owned rights. Reference herein to any specific commercial product, process, or service by trade name, trademark, manufacturer, or otherwise, does not necessarily constitute or imply its endorsement, recommendation, or favoring by the United States Government or any agency thereof. The views and opinions of authors expressed herein do not necessarily state or reflect those of the United States Government or any agency thereof. 


\title{
Progress Letter Report on
}

\section{U-Frame Test Setup and Bending Fatigue Test for Vibration Integrity Study (Out-of-cell fatigue testing development, Task 2.4)}

\author{
Jy-An John Wang ${ }^{1}$ \\ Hong Wang ${ }^{1}$ \\ Thomas Cox ${ }^{1}$ \\ Chuck Baldwin ${ }^{2}$ \\ ${ }^{1}$ Materials Science and Technology Division \\ ${ }^{2}$ Fuel Cycle and Isotopes Division
}

Bruce B. Bevard

Project Manager

Reactor \& Nuclear Systems Division

Oak Ridge National Laboratory

Date Published: July 2013

\author{
Prepared by \\ OAK RIDGE NATIONAL LABORATORY \\ P.O. Box 2008 \\ Oak Ridge, Tennessee 37831-6285 \\ managed by \\ UT-BATTELLE, LLC \\ for the \\ U.S. DEPARTMENT OF ENERGY \\ under contract DE-AC05-00OR22725
}




\section{Executive Summary}

Vibration integrity of high burn-up spent nuclear fuel in transportation remains to be a critical component of US nuclear waste management system. The structural evaluation of package for spent fuel transportation eventually will need to see if the content or spent fuel is in a subcritical condition. However, a system for testing and characterizing such spent fuel is still lacking mainly due to the complication involved with dealing radioactive specimens in a hot cell environment. Apparently, the current state-of-the-art in spent fuel research and development is quite far away from the delivery of reliable mechanical property data for the assessment of spent fuels in the transport package evaluation.

Under the sponsorship of US NRC, ORNL has taken the challenge in developing a robust testing system for spent fuel in hot cell. An extensive literature survey was carried out and unique requirements of such testing system were identified. The U-frame setup has come to the top among various designs examined for reverse bending fatigue test of spent fuel rod. The U-frame has many features that deserve mentioned here:

- Easy to install spent fuel rod in test;

- Less linkages than in conventional bending test setup such as three-point or four-point bending;

- Target the failure mode relevant to the fracture of spent fuel rod in transportation by focusing on pure bending;

The continuous calibrations and modifications resulted in the third generation (3G) U-frame testing setup.

- Rigid arms are split along the LBB axis at rod sample ends. For each arm, this results in a large arm body and an end piece.

- Mating halves of bushings were modified into two V-shaped surfaces on which linear roller bearings (LRB) are embedded.

- The rod specimen is installed into the test fixture through opening and closing slide endpieces.

The 3G apparently has addressed major issues of setup identified in the previous stage and been proven to be eligible to be further pursued in this project.

On the other hand, the purchase of universal testing machine or Bose dual LM2 TB was completed and the testing system was delivered to ORNL in August 2012. The preliminary confirmation of the system and on-site training were given by Bose field engineer and regional manager on 8/1-8/2/2012. The calibration of Bose testing system has been performed by ORNL because the integration of ORNL setup into the Bose TestBench occurred after the installation. Major challenge with this process arose from two aspects: 1) the load control involves two load 
cells, and 2) U-frame setup itself is a non-standard specimen. ORNL has been able to implement the load control through Cycle Indirect along with pinning the U-frame setup.

Two meetings with ORNL hot-cell group (November 2012 and January 2013) were held to discuss the potential issues with both epoxy mounting of rigid sleeve and U-frame setup. Many suggestions were provided to make the procedure friendlier to the manipulator in hot cell. Addressing of these suggestions resulted in another cycle of modifications of both vise mold and setup.

The initial meeting with ORNL I\&C group occurred in November 2012 with regard to the Bose cable modification and design of central panel to integrate the cables and wires. The first round of cable modification and central panel fabrication was completed in February 2012. The testing with the modified cables exhibited substantial noises and the testing system was not shown to be stable. It was believed the cross talk was responsible to the noise, and a central panel with a better grounding and shielding was highly recommended. The central panel has been re-designed and fabricated in March 2013. In the subsequent period, the ORNL made substantial effort to debug the noises with the load cell channel, and to resolve the noises and nonlinearity with RDP LVDTs related to the integration of RDP LVDTs to Bose system.

At the same time, ORNL has completed the verification tests of Bose test system, including cycle tests under reversal bending in load control, bending tests under monotonic load, and cycle tests under reversal bending in load control on MTS machine to verify the results of Bose machine. These results are shown to be consistent under equivalent loading conditions, especially for the cycle tests.

Rad hardened LVDTs will be incorporated into the Bose system once received, and $10 \mathrm{~Hz}$ tests will be completed in the next step. The schedule for the final check of the Bose system is being finalized before the system delivered to the hot cell. 


\section{Contents}

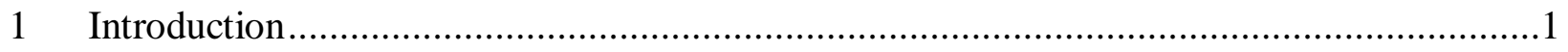

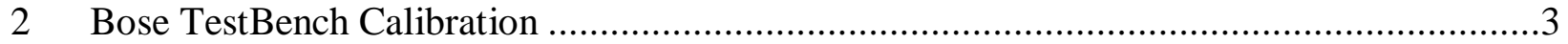

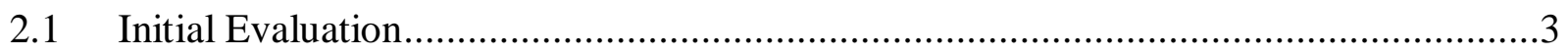

2.2 Calibration and Control Mode Development ................................................................4

3 Integration of U-frame with Bose TestBench ..................................................................6

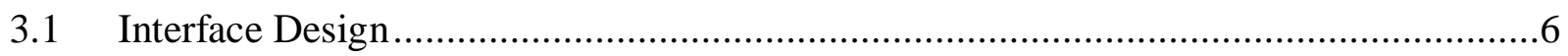

3.2 Interface Modification for Improved Reliability ……..................................................

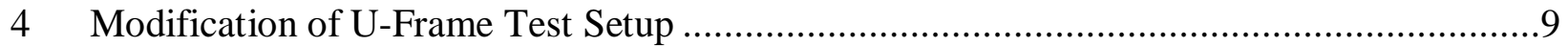

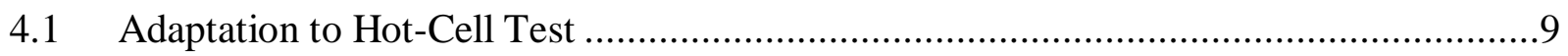

4.2 Inspection and Maintenance .....................................................................................11

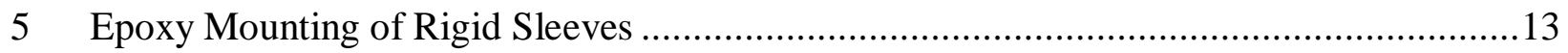

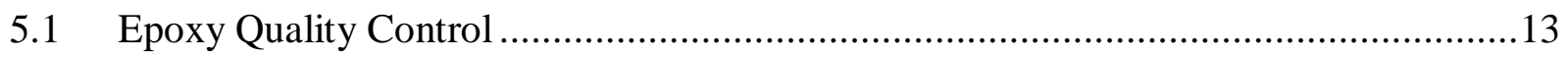

5.2 Epoxy Mounting Procedure....................................................................................13

5.3 Epoxy Durability under Radiation ........................................................................

5.4 Adaptation of Vise Mold to Hot-Cell Test ....................................................................14

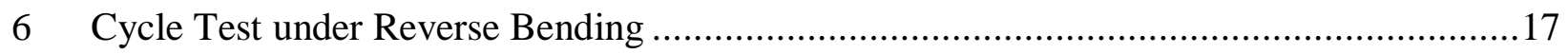

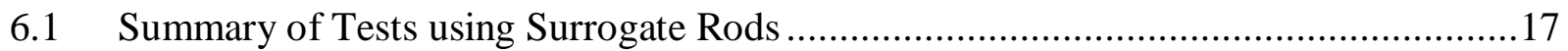

6.2 Cycle Test under Load Control..................................................................................19

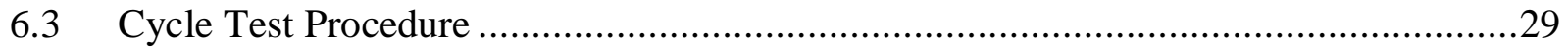

$7 \quad$ Bending Testing under Monotonic Loading ....................................................................

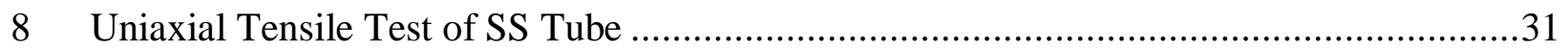

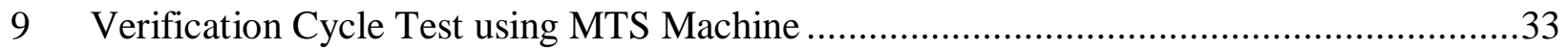

10 Cable Adaptation and Central Panel .................................................................................39

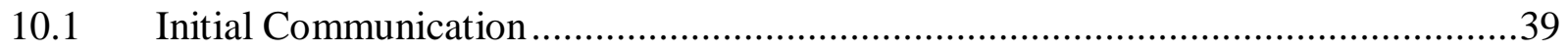

10.2 Central Panel and Alpha Plug ..................................................................................

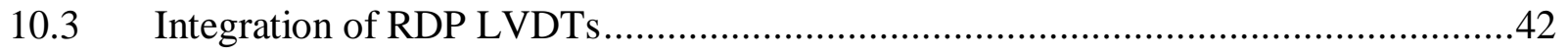

$10.4 \quad$ Rad Hardened LVDTs for Bose TestBench.............................................................

11 Summary and Future Work........................................................................................45

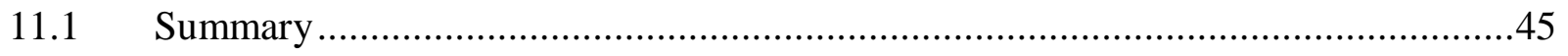

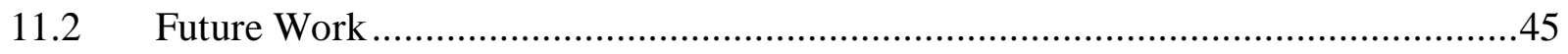




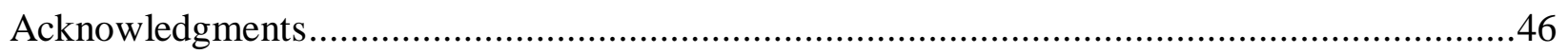

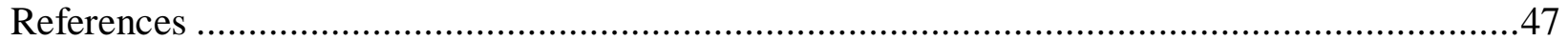




\section{List of Figures}

Figure 1 Installed Bose Dual LM2 TB...........................................................................

Figure 2 The pinned U-frame testing setup on Bose TestBench .........................................4

Figure 3 Test using polycarbonate tube .................................................................................5

Figure 4 U-frame integrated to Bose dual LM2 TB.......................................................6

Figure 5 Modification of interface of U-frame to Bose test bench with two stands moved

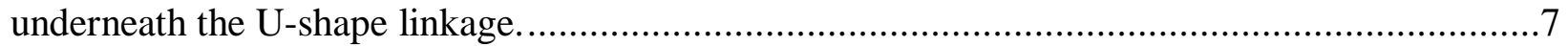

Figure 6 Cartridge embedded with roller bearings installed to replace the wheeled carrier..........8

Figure 7 modification of $\mathrm{U}$-frame for improved reliability ................................................9

Figure 8 Adaptation of U-frame setup to hot-cell test ........................................................10

Figure 9 Suggested modification of U-frame setup for hot-cell test.........................................10

Figure 10 Examination of U-frame test setup and maintenance..............................................12

Figure 11 Vise mold modified for hot cell test...............................................................15

Figure 12 Moment as a function of cycles or cycles to fail. No failure was observed for SSAP13, SSAP21, and SSAP26. The SSAP26 was continued at $10 \mathrm{~Hz}$ after $4 \times 10^{6}$ cycles at $5 \mathrm{~Hz}$. SSAP25 was irradiated 2 weeks under a sandwich configuration between 6- and 7-fuel rod layers.

SSAP27 irradiated 4 weeks.

Figure 13 Variation of (a) curvature, (b) moment, and (c) rigidity based on on-line monitoring of SSAP11: $\pm 200 \mathrm{~mm}, 5 \mathrm{~Hz}$.

Figure 14 Variation of (a) curvature, (b) moment, and (c) rigidity based on on-line monitoring of SSAP12: $\pm 200 \mathrm{~mm}, 5 \mathrm{~Hz}$.

Figure 15 Variation of (a) curvature, (b) moment, and (c) rigidity based on on-line monitoring of SSAP13: $\pm 200 \mathrm{~mm}, 5 \mathrm{~Hz}$.

Figure 16 Variation of (a) curvature, (b) moment, and (c) rigidity based on on-line monitoring of SSAP14: \pm 250 mm, $5 \mathrm{~Hz}$.

Figure 17 Variation of (a) curvature, (b) moment, and (c) rigidity based on on-line monitoring of SSAP15: $\pm 250 \mathrm{~mm}, 5 \mathrm{~Hz}$.

Figure 18 Variation of (a) curvature, (b) moment, and (c) rigidity based on on-line monitoring of SSAP16: $\pm 300 \mathrm{~mm}, 5 \mathrm{~Hz}$.

Figure 19 Variation of (a) curvature, (b) moment, and (c) rigidity based on on-line monitoring of SSAP17: $\pm 300 \mathrm{~mm}, 5 \mathrm{~Hz}$.

Figure 20 Variation of (a) curvature, (b) moment, and (c) rigidity based on on-line monitoring of SSAP21: \pm 200 mm, 5 Hz.

Figure 21 Variation of (a) curvature, (b) moment, and (c) rigidity based on on-line monitoring of SSAP23: $\pm 250 \mathrm{~mm}, 5 \mathrm{~Hz}$.

Figure 22 Variation of (a) curvature, (b) moment, and (c) rigidity based on on-line monitoring of SSAP24: $\pm 300 \mathrm{~mm}, 5 \mathrm{~Hz}$.

Figure 23 Variation of (a) curvature, (b) moment, and (c) rigidity based on on-line monitoring of 
Figure 24 Variation of (a) curvature, (b) moment, and (c) rigidity based on on-line monitoring of SSAP26: $\pm 200 \mathrm{~mm}, 5 \mathrm{~Hz}$.

Figure 25 Variation of (a) curvature, (b) moment, and (c) rigidity based on on-line monitoring of SSAP27: $\pm 300 \mathrm{~mm}, 5 \mathrm{~Hz}$.

Figure 26 Three static bending tests were completed w/ max disp. of $20 \mathrm{~mm}$ at loading points of

U-frame setup. 30

Figure 27 Uniaxial tensile test results: (a) strain - stress curve, (b) initial part of strain-stress curve, (c) failed specimens and (d) fracture surface. SS04, OD 0.4375”, ID 0.3815, GL 1.625”; E $=176 \mathrm{GPa}$; YS at $0.2 \%$ offset $=325 \mathrm{MPa}$; UTS $=664 \mathrm{MPa}$. 31

Figure 28 Uniaxial tensile test results: (a) strain - stress curve, (b) initial part of strain-stress curve, (c) failed specimens and (d) fracture surface. SS05 (SS-MOX-02); OD 0.4365”, ID 0.381”, 1.625” GL; E = 195 GPa; YS at 0.2\% offset = $292 \mathrm{MPa}$; UTS = $664 \mathrm{MPa}$. .32

Figure 29 Moment as a function of cycles or cycles to fail. SSAP30, SSAP33 and SSAP36 had 440C hardened rigid sleeves; SSAP35 is held off for SSAP36 for hardened rigid sleeve verification testing. .33

Figure 30 Variation of (a) curvature, (b) moment, and (c) rigidity based on on-line monitoring of SSAP28: $\pm 250 \mathrm{~mm}, 2 \mathrm{~Hz}$.

Figure 31 Variation of (a) curvature, (b) moment, and (c) rigidity based on on-line monitoring of SSAP29: $\pm 250 \mathrm{~mm}, 2 \mathrm{~Hz}$. .35

Figure 32 Variation of (a) curvature, (b) moment, and (c) rigidity based on on-line monitoring of SSAP30: $\pm 250 \mathrm{~mm}, 2 \mathrm{~Hz}$. .35

Figure 33 Variation of (a) curvature, (b) moment, and (c) rigidity based on on-line monitoring of SSAP31: $\pm 300 \mathrm{~mm}, 2 \mathrm{~Hz}$. .36

Figure 34 Variation of (a) curvature, (b) moment, and (c) rigidity based on on-line monitoring of SSAP32: $\pm 300 \mathrm{~mm}, 2 \mathrm{~Hz}$. .36

Figure 35 Variation of (a) curvature, (b) moment, and (c) rigidity based on on-line monitoring of SSAP33: $\pm 300 \mathrm{~mm}, 2 \mathrm{~Hz}$. .37

Figure 36 Variation of (a) curvature, (b) moment, and (c) rigidity based on on-line monitoring of SSAP35: $\pm 200 \mathrm{~mm}, 2 \mathrm{~Hz}$. .38

Figure 37 Variation of (a) curvature, (b) moment, and (c) rigidity based on on-line monitoring of SSAP36: $\pm 200 \mathrm{~mm}, 2 \mathrm{~Hz}$. .38

Figure 38 Concept of central panel for bending fatigue testing system.................................39

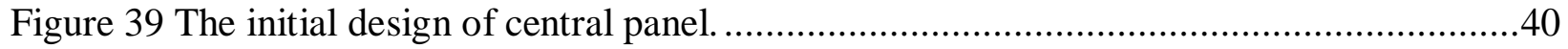

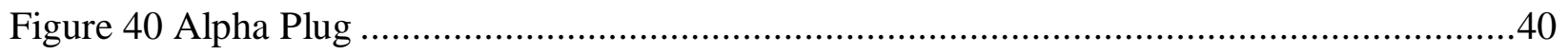

Figure 41 Re-designed central panel...........................................................................41

Figure 42 Central panel mounted to the Bose breadboard with re-worked power cables ...........42

Figure 43 Calibration and integration of RDP LVDTs.....................................................42

Figure 44 A nonlinear response was revealed between the target and meter reading in WinTest7.

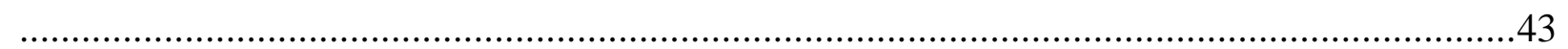

Figure 45 Linearity of RDP LVDT channels obtained after re-wired. ..................................44 


\section{List of Tables}

Table 1 Summary of verification tests using surrogate rods* ..........................................17 


\section{Introduction}

Testing high burn-up spent fuel presents challenges in many aspects from specimen preparation, specimen installation, to mechanical loading, load control, measurements, data acquisition, and specimen disposal. These aspects are complicated by the radioactivity of test specimens. Unique features of the test and testing specimens demand the test plan to address these issues from very beginning.

The main considerations for testing the high burn-up SNF rods can be summarized as follows:

- High burn-up SNF rods have a composite structure with multi-scale discontinuities.

- Discontinuities and stresses perpendicular to the longitudinal axis of the rod specimen will dominate the rod failure under cyclic bend loading during transportation.

- Shearing-dominant fractures and contact-induced damage in a conventional four or threepoint bending setup readily induce failures away from the target locations.

- A free-fixed (frixed) type of boundary condition is required for the contact point design for the rod specimen to rotate freely about an axis in the neutral plane. This significantly increases the degree of difficulty in design.

- Installation of the testing setup in a hot-cell environment imposes strict constraints on the test design.

An extensive literature survey revealed a variety of bending fatigue testing methods being developed, including cantilever beam bending, three-point/ four-point bending, and pure bending, as well as variants considering environmental factors, particularly temperature. The subsequent concept design study resulted in the development of a U-frame testing system that is capable of performing reversal bending fatigue testing. ${ }^{1}$

3-D finite element analysis (FEA) was conducted and the U-frame testing setup concept was further refined. Engineering design has been carried out to implement the concept of U-frame assisted bending fatigue testing. The first set of engineering drawings was submitted to procurement for machining solicitation in May 2011. ${ }^{2}$ Fabrication of components was finished one month later. It is worth noting that the initial design didn't use the linear bearing as suggested by the concept design. This was because our FEA demonstrated that the pure bending could be achieved using only the compliant layers.

The U-frame setup has been modified and refined a number of times. The third generation (3G) U-frame has been proposed to be pursued in the integration to the Bose dual LM3 TB test system, featuring: ${ }^{2}$

- $\quad$ Rigid arms are split along the LBB axis at rod sample ends. For each arm, this results in a large arm body and an end piece. 
- Mating halves of bushings were modified into two V-shaped surfaces on which linear roller bearings (LRB) are embedded.

- The rod specimen is installed into the test fixture through opening and closing slide endpieces.

Additional modification of ORNL U-frame setup was involved with an exchangeable roller bearing house made of hardened SS for the hot-cell replacement in case the rolling surfaces are substantially damaged. ${ }^{3}$

The work reported here focuses on the incorporation of ORNL U-frame into the Bose testing system setup that has been conducted upon the receiving of Bose system in August 2012. It will cover the calibration of Bose system, integration and modification of U-frame setup, epoxy mounting of rigid sleeves into the surrogate rod, verification tests, Bose cable adaptation to hotcell testing, integration of RDP LVDTs, and test procedure development. 


\section{Bose TestBench Calibration}

\subsection{Initial Evaluation}

Figure 1 shows Bose Dual LM2 TB system that is installed in L218, 4515. The Bose TestBench will be hosted in this lab until the testing system is ready to be delivered to the hot cell.

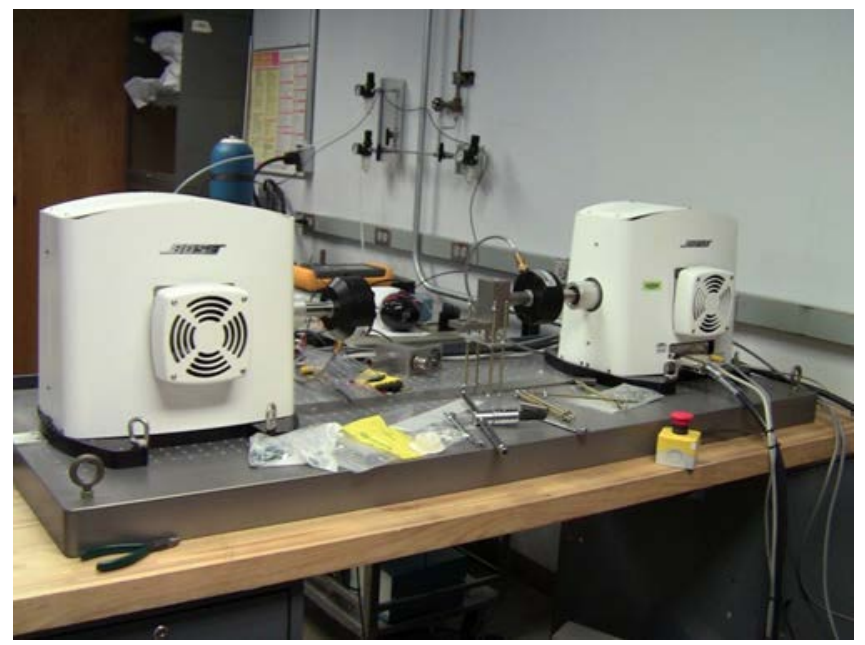

Figure 1 Installed Bose Dual LM2 TB

Several meetings were held to discuss issues related to the hot cell testing.

1) Cable and wire connectors and central hub. It has been immediately realized that to plug the cable connectors of linear motors into the sockets is not feasible for the manipulators to carry out such operation in hot cell. In addition, the accessible space between the power sockets and the breadboard is limited. A concept of central hub or panel has been proposed to integrate all the cables and wires.

2) Cable and wire extension. $15 \mathrm{ft}$ length is needed for all of the electrical connections from the in hot cell test bench to the outside controller and data acquisition equipment.

3) Plastic component replacement. Some Bose functional and structural components are made of plastic, including the LVDT mounts, electric fans, and motor mounts. Some of the plastic components should be replaced by metal components.

4) Shielding. The linear motors will be subjected to the radioactive contaminant and dust in hot cell environments. A simple (non-rad) protective cover will be required.

5) Sensors. Current LVDTs are used in room temperature for the out-of-cell development. Sensors and amplifiers for hot-cell use will be required. 


\subsection{Calibration and Control Mode Development}

Many cycles of U-frame modification and Bose tuning were conducted to understand experimental results and confirm the performance of system. The tuning and testing of integrated system were shown to be fine in displacement control mode. Major issue exists on the load control mode. It has been observed that the U-frame setup drifted significantly if the load control was used. This is mainly due to the following reasons:

- Dual load cells are involved in load control.

- A U-frame setup instead of standard specimen is used.

After quite a number of tests, ORNL developed a technical approach to addressing the drifting by pinning the side connecting plate of U-frame to the sliding plate of frontal stand, Figure 2. It has been shown that the Cycle Indirect ${ }^{4}$ along with the proposed pinning is quite effective in eliminating the drifting of setup while, at the same time, implementing the required load control. Subsequent cycle tests using SSAP11, SSAP12, and SSAP13 were conducted under $5 \mathrm{~Hz}$, $\pm 200 \mathrm{~N}$. The output indicated a quite consistent load level during all of the cycle tests. The first two tests generated lifetimes of $678 \mathrm{~K}$ and 936 cycles with about 40 to $42 \%$ drop of flexural rigidity before fractures. The fractures all occurred within the gage sections and the specimen hold areas appeared to be fine. The last specimen was still running with about only $11 \%$ drop of rigidity after more than $1.7 \mathrm{M}$ cycles. The observed difference in lifetimes was likely due to the compositions and machining of specimen which came from a different batch of preparation.

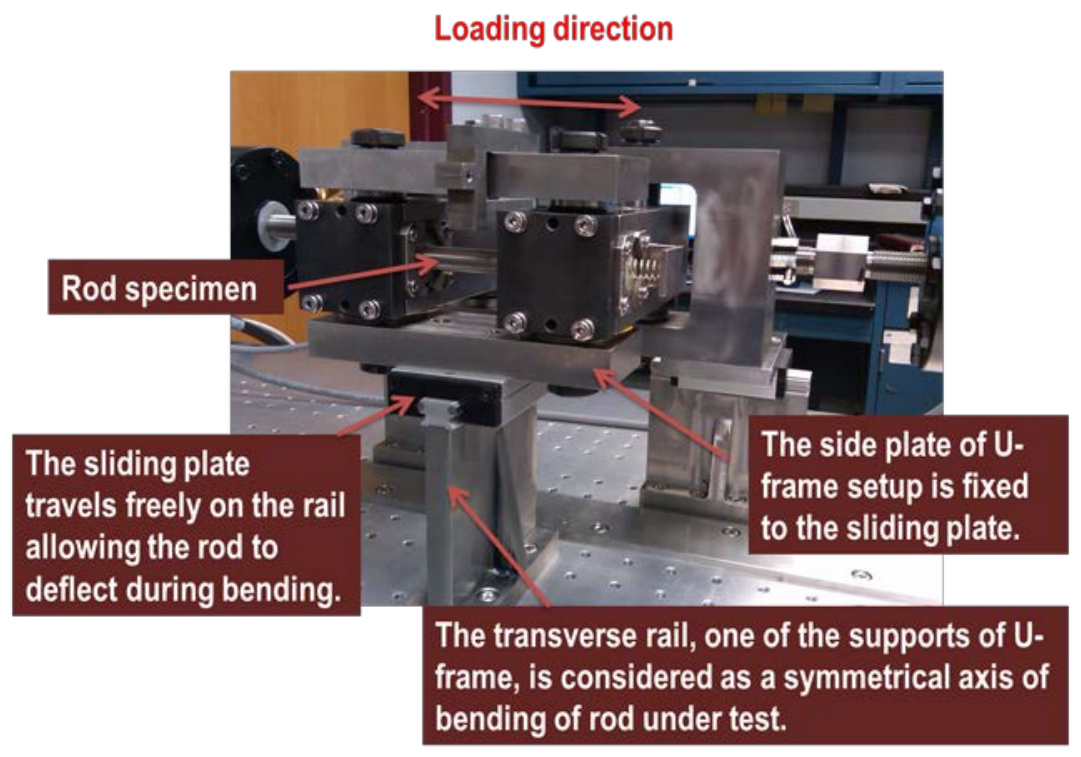

Figure 2 The pinned U-frame testing setup on Bose TestBench 
A plan has been made also to test Bose system using a standard specimen. The purpose of test using the standard specimen is to evaluate the effect of U-frame setup on the control and tuning of Bose system. The specimen is a polycarbonate tube to target the stiffness of the U-frame setup with a rod specimen loaded, 150N/mm under $200 \mathrm{~N}$. A polycarbonate tube sized OD $1 / 2 ”$, ID 3/8", 12" length was used, Figure 3.

The polycarbonate tube test was performed by using the suggested method after the Bose adding an additional channel "DispDiff" into the project file as control channel. Tuning with Axial 1 in load control at $10 \mathrm{~Hz}, 300 \mathrm{~N}$, and Axial 2 in "DispDiff" in ramping was completed, ${ }^{5}$ but the subsequent tests displayed that the Disp1 and 2 were out of phase, even though no drifting was observed for these two channels. Additional compensations were used in the control but the two channels were still out of phase. It has been further observed that the phase delay was actually reduced with the decreasing frequency used in the load control in the Axial 1. Considering the frequency response of two channels in the case of standard specimen, it is believed that the outof-phase originally comes from the control algorithm. Such observation was feedback to Bose. While Bose may still work on the load control mode, ORNL has decided to use the Cycle Indirect along with the developed pinning technique to continue the cycle test in the following work.

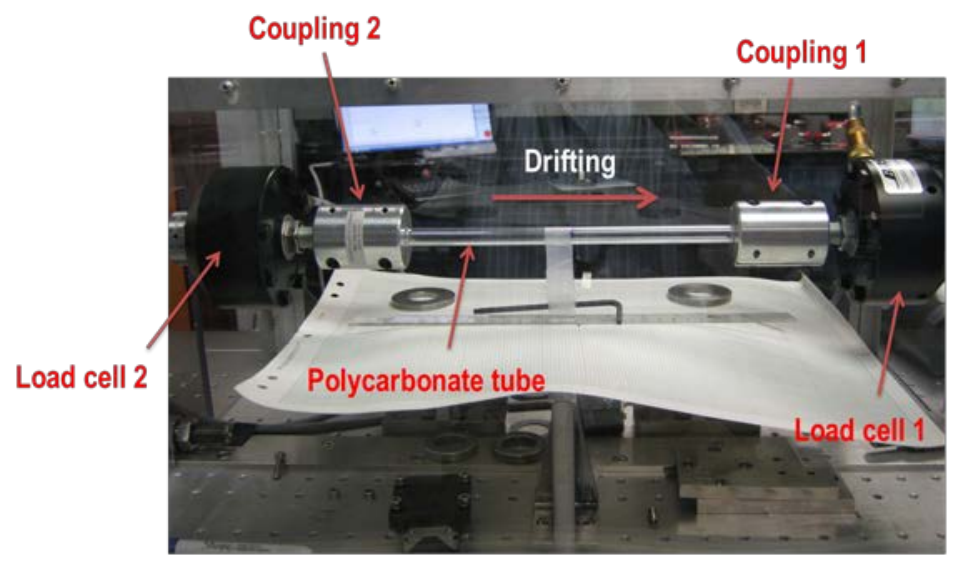

- Specimen targets the stiffness of U-frame, $\sim 150 \mathrm{~N} / \mathrm{mm}$

- Polycarbonate tube is considered: Young's modulus $2.5 \mathrm{GPa}$ ○ $1 / 2 "$ OD, 3/8" ID, 12" length will give $455 \mathrm{~N} / \mathrm{mm}$

Figure 3 Test using polycarbonate tube 


\section{Integration of U-frame with Bose TestBench}

\subsection{Interface Design}

Interface of U-frame to the Bose dual LM2 TB involves the following issues.

- The interface of U-frame with breadboard. To ensure the mobility and alignment of Uframe during the reverse bending test, high precision linear bearing (INA LFKL20SF) are used under both the rigid arms and side connection plates. In the case of rigid arms, a bracket makes the attachment of the linear bearing to the arms. Three stands are designed to support the linear bearings, on the top of which is attached the rails.

- The interface of U-frame with load cells. Two turnbuckles are used to link the U-frame to load cells. The original Y-linkage is modified into a U-shape linkage. On the bottom of the structure, 6 columns are surrounding the threaded hole to provide the stop to the shaft of turnbuckle. A pin is used for each turnbuckle.

The interface components are fabricated and assembled on Bose dual LM2 TB as shown in Figure 4. Assembled version of interface made an important change on the ball bearing shafts on the lower side of rigid arms. Thrust bearings are installed to provide vertical support to the rigid arms. Initial run showed that the system worked as designed.

The concerns were raised about the performance of linear bearing for the support of U-shape linkage. The linear bearings are subjected to the bending effect due to the eccentric arrangement of U-linkage and the stands. In the modified interface design, the stands are moved underneath the U-shape linkage as shown in Figure 5.
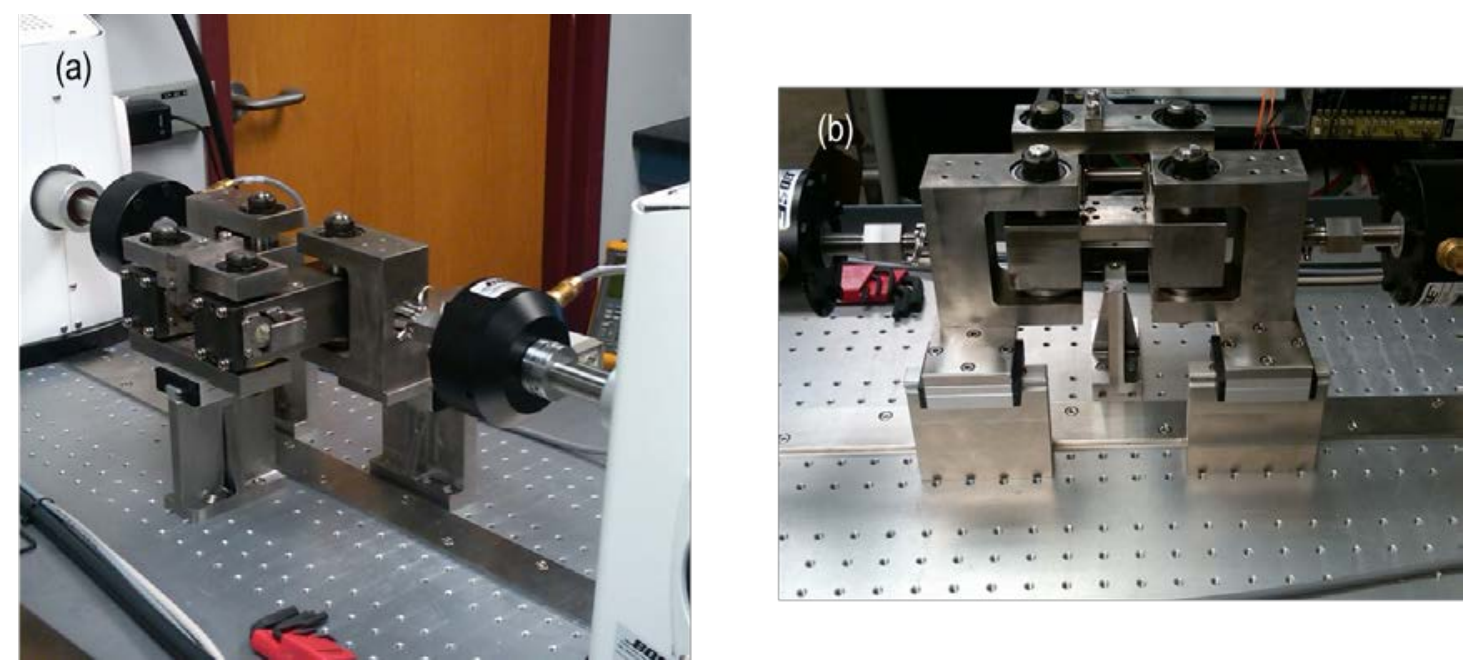

Figure 4 U-frame integrated to Bose dual LM2 TB 


\subsection{Interface Modification for Improved Reliability}

First, the rear stands that are aligned in the longitudinal direction have been replaced by the new stands. The new design has the supporting rails arranged directly underneath the U-shaped beams (Figure 5) and therefore, the weights of components from upper can be transferred into the breadboard without any concerns with the bending on the sliding plates.

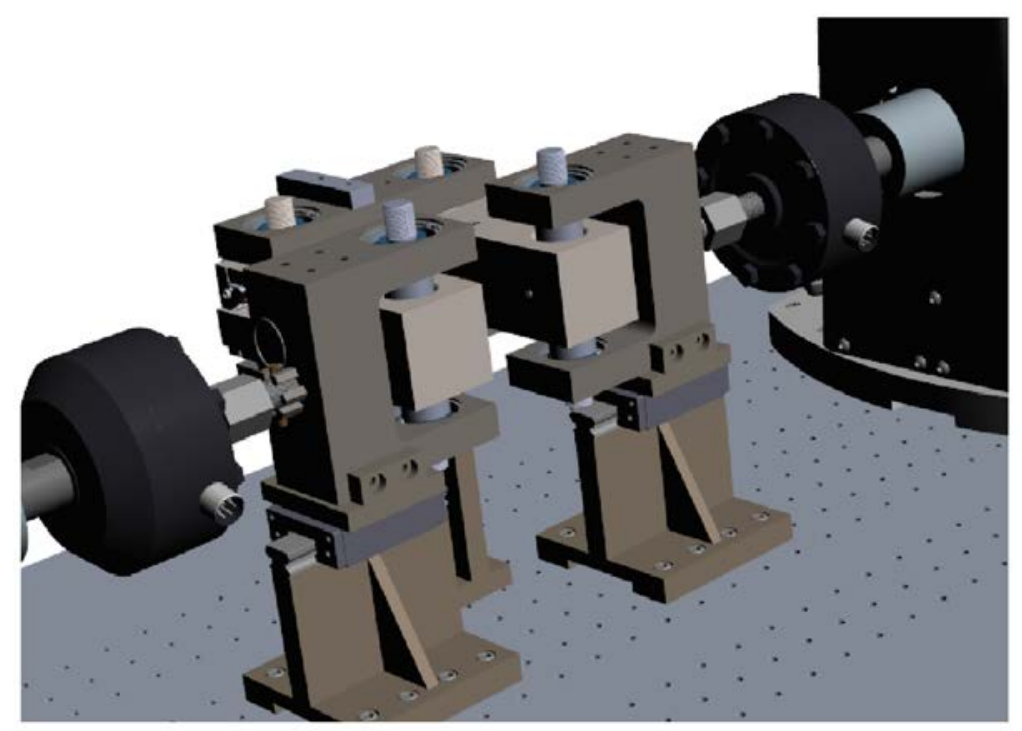

Figure 5 Modification of interface of U-frame to Bose test bench with two stands moved underneath the U-shape linkage.

Second, a major modification was made to the interface between the U-frame and the test bench. It has been shown that the contact of the sliding cartridges with the supports created extensive wear during extended cycle tests. A cartridge embedded with linear roller bearings, Figure 6, was evaluated as a contact mechanism in the interface. The components were fabricated and installed. The cartridges are fixed on the top of two back supports to replace the original wheel-rail contact pairs. The new interface design apparently is more efficient in enabling sliding and transferring upfront load. A follow-up test at $200 \mathrm{~N}$ and $5 \mathrm{~Hz}$ accumulating more than 4 million cycles and shows that the system is quite stable. This is due to the use of the multiple surface-to-line contacts in the new design with the linear roller bearings. 


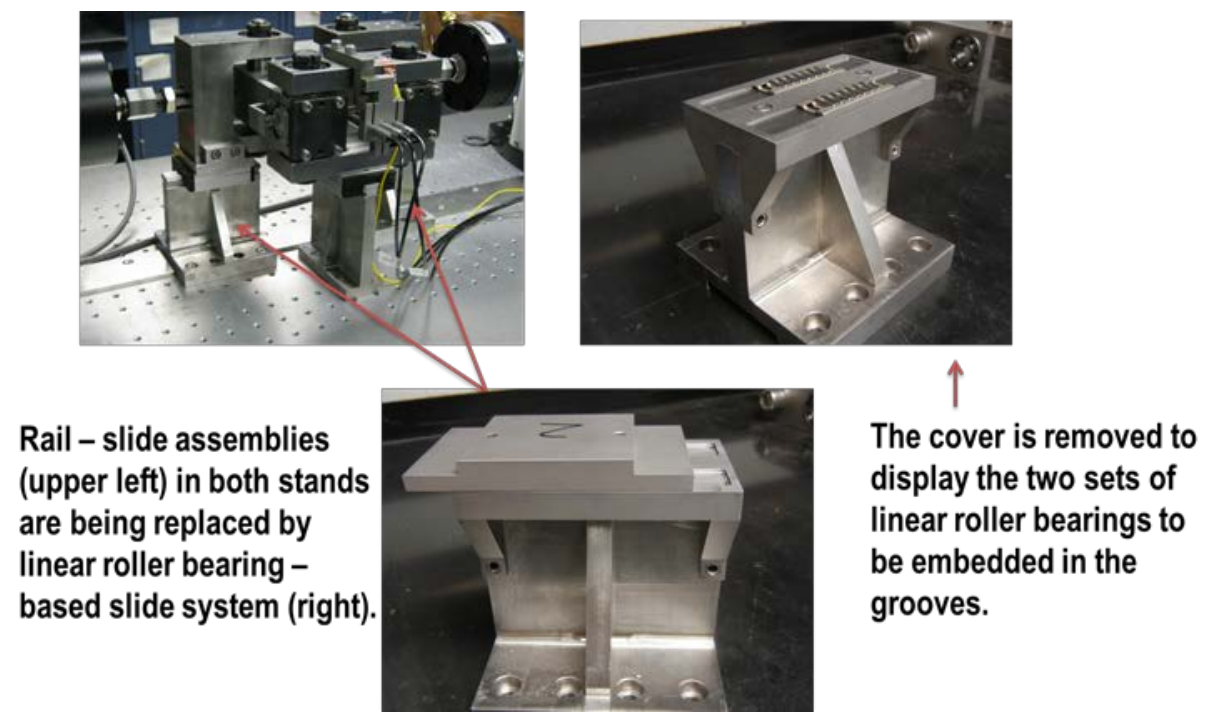

Figure 6 Cartridge embedded with roller bearings installed to replace the wheeled carrier. 


\section{Modification of U-Frame Test Setup}

\subsection{Adaptation to Hot-Cell Test}

First, the original ball bearings used in the hinged corners of U-frame setup all have been replaced by the tapered roller bearings (Figure 7). The necessity of using tapered bearing has been discussed in the earlier weekly brief of last month. The tapered surfaces provide by the tapered bearing offers a certain capacity of thrust loading, and have a much more reliability in the environment where the axial loading is involved. This is the case for the horizontal setup where the weights of rigid arms need to be transferred stably onto the sliding plates underneath, whilst a regular ball bearing is mainly designed to carry the load in the radial direction.

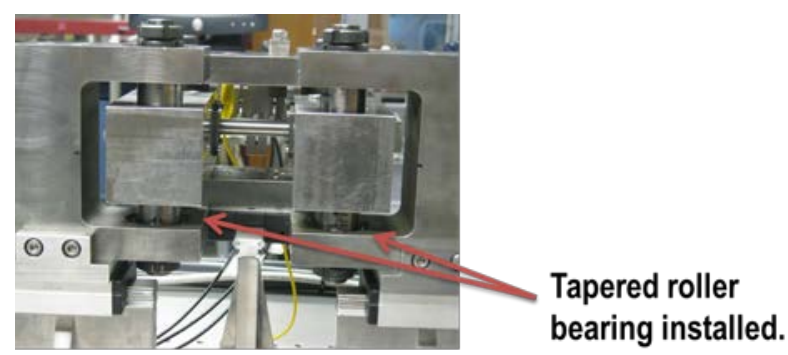

Figure 7 modification of U-frame for improved reliability

The first meeting with the hot-cell staff occurred in Nov 2012 to discuss potential issues with the current test setup, including Bose machine cables and wires. The steps that require manipulators to complete installation of specimens appear to be achievable. However, some modifications appear to be warranted to include (Figure 8): 1) Guide rods used for support and to enable the end block to slide need to be longer. 2) Bolts need to be changed from a female type into a male type. 3) The compression spring caps on both ends of the rod specimen block the view of the manipulator operator making it hard to locate the mounting bolts behind the caps. 
 from current female type into male type. block the view of manipulator and it is hard to locate the mounting bolts behind the caps.

- It is studied to either lower the cap or use a higher cap bolt.

Guiding rods (not installed in the setup shown, but made) for supporting and enabling the end block to slide need to have a larger length.

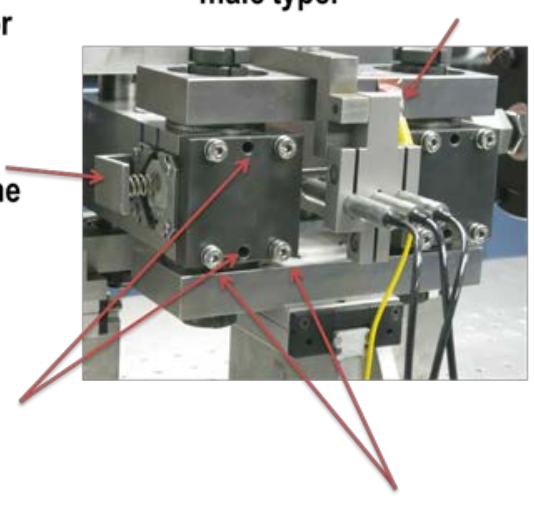

Tightening bolts need to change from current female type into male type.

Figure 8 Adaptation of U-frame setup to hot-cell test

The second meeting with hot cell group occurred in Jan 2013 to examine the bending fatigue testing setup. A series of the suggestions were also provided as a result of such meeting. 1) Make LVDT bracket with a locking V-groove. 2) Insert dowel pin stops on spring retainers. 3) Create inserts to prevent specimens from dropping when changed and another insert to prevent specimen dust from dropping upon fracture. 4) Chamfer rigid sleeves and spring retainers. These suggestions have all been incorporated into the current setup.

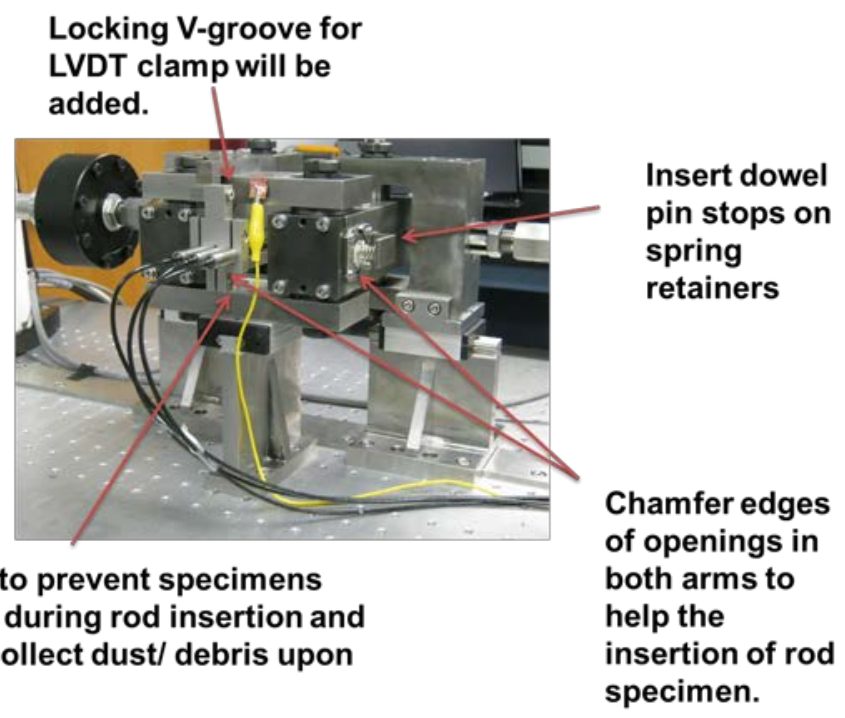

Figure 9 Suggested modification of U-frame setup for hot-cell test 


\subsection{Inspection and Maintenance}

A thorough inspection of Bose testing machine was conducted in April 2013, Figure 9. More than 10 million of cycles have been finished over 14 SSAP rods since the commencement of Bose machine in the August of 2012. The examination showed that there was substantial wear on the interface components between the U-frame and the stands, namely the roller bearing sets and bearing houses. The old roller bearing sets were replaced, and rolling surfaces cleaned and greased for the improved endurance. At the same time, Bose load cells were re-oriented to have the sense elements located on the backside of the load cell body so they are more protected from the radiation effect of the spent fuel rod. One of the load cell channels was found out to be a little biased. It is suggested to have a detail calibration and investigation when the Bose engineer visits the ORNL for final check of the system. A follow-up test under $+/-200,10 \mathrm{~Hz}$, using SSAP38 in May 2013 showed that the re-assembled testing setup works fine.

(a) Initial state before test system disassembly

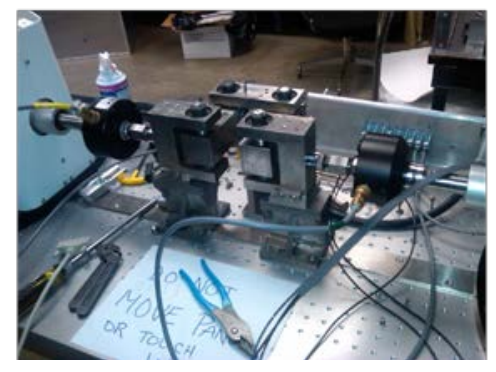

(c) Free turn-knuckle from both arms

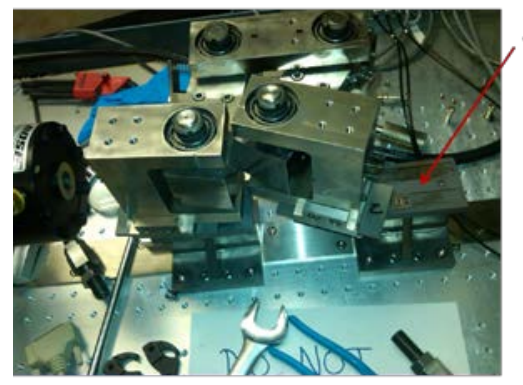

(b) Removal of linking turn-knuckle

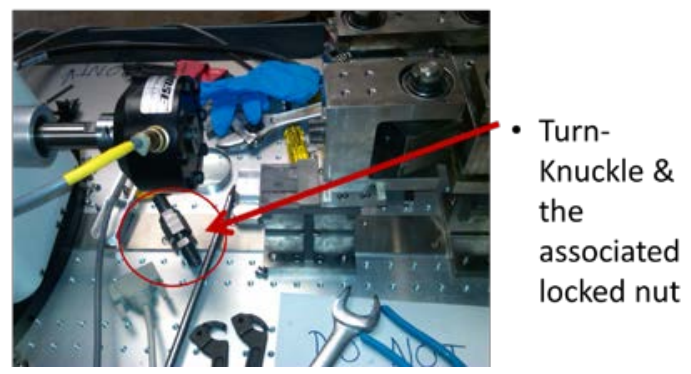

(d) Removal of U-bent frame

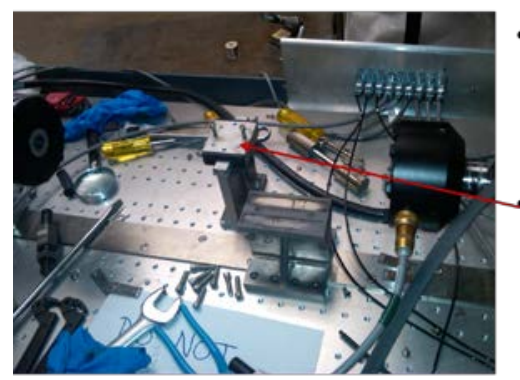

- Ready to reverse the load cell orientation

Central divide/fixed plate 
(e) Installation of anchor plate for releasing spiral washer from load cell

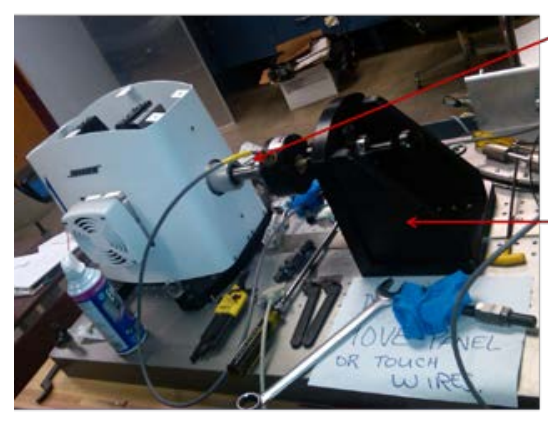

\section{$3000 \mathrm{~N}$ load} needs to be applied to the anchor plate to remove the spiral washer Anchor plate

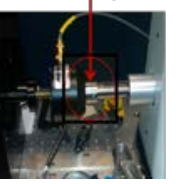

(g) Rolling surfaces were cleaned and treated by grease for enhanced reliability.
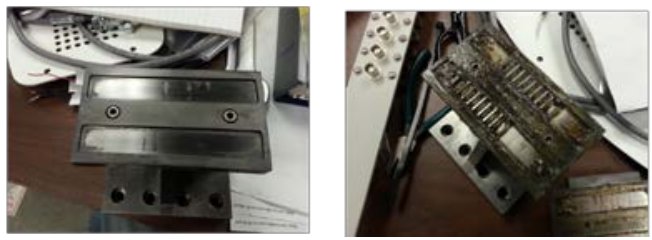

(f) Significant wear observed from the support plate $\&$ needle roller bearing

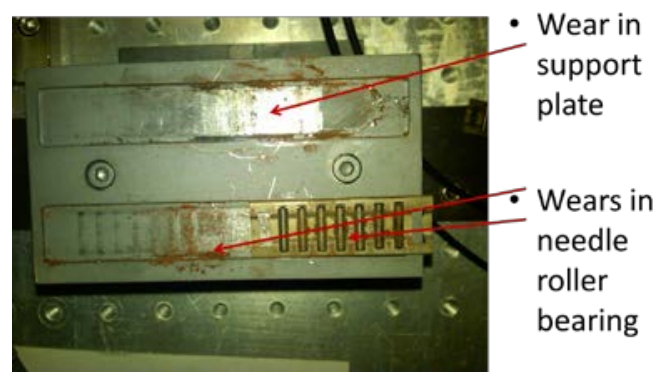

(g) Load cell was re-oriented to have the sense element in the back.

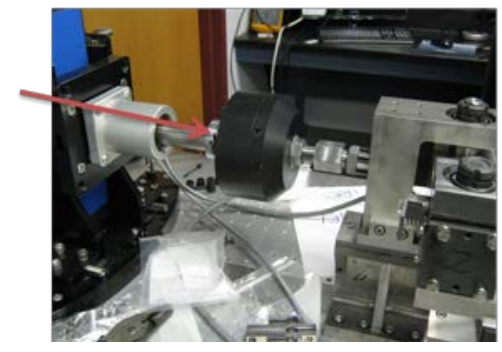

Figure 10 Examination of U-frame test setup and maintenance 


\section{Epoxy Mounting of Rigid Sleeves}

\subsection{Epoxy Quality Control}

The purpose of controlling the epoxy material in the rigid sleeve grips is to preclude bubbles or voids in the rigid sleeves and excess epoxy running over the mold. The epoxy casting technique relies on the machined tolerance at the bottom of the chamber to stop the epoxy from leaking out when the rigid sleeve is inserted. Any leakage usually required a follow-up procedure to clean the mold. Two sealing methods have been explored.

- The first uses a rubber gasket attached to both ends of rigid sleeve.

- The second method employs an O-ring placed at a pre-determined position of the rod.

Both methods have been found to be effective only to a limited degree in controlling the epoxy leakage. Major problems were noted: 1) the used rubber is very soft and cannot hold the epoxy in the rigid sleeve when the loaded rigid sleeve is shifted from the table into the mold chamber. 2) The O-ring stopped the rigid sleeve from fully reaching into the chamber. As a result, the rod specimens usually have an extra gage length when prepared using O-rings. The following approaches are proposed in the current epoxy mounting procedure to address these issues:

- A metal disk is spot-welded to close the bottom end of rigid sleeve. This disk apparently works better in holding the epoxy when the grip is transported to the mold.

- Additionally, the amount of epoxy injected into the rigid sleeves was tracked by weight. The weight of epoxy used to fill the sleeves has been identified by several cycles of trialand-error. With this measure, the excessive epoxy can be minimized to a greater extent.

- The compression through a large size U-clamp was used in the modified cast process to drive the rigid sleeve into the bottom of chamber. The compression force was shown to be very effective in eliminating the extra gage length and, at the same time, enhancing the flow of epoxy.

When using the current vise mold, the preparation of one rod specimen using epoxy casting can be completed within one day (or 24 hour period). This is accomplished through mounting one rigid sleeve and rotating the mold to mount another rigid sleeve. This duration is still considered to be overly long. An attempt was made to build a mold for multiple specimen preparations. The drawings were prepared and a solicitation was made for machining this new device. However, upon further consideration and discussion with NRC, it was decided that this plan is not really feasible and the work on this approach was stopped.

\subsection{Epoxy Mounting Procedure}

An epoxy mounting procedure for rigid sleeves is give in the following including the surrogate rod preparation ahead of it.

1. Workspace preparation 
2. Create epoxy ring

3. Insert alumina pellet

4. Repeat the step 2 and 3 until there are 10 pellets in the rod. Pellets will bulge from ends

5. Clamp the rod loaded with 10 alumina pellets. Please note the bubble filled epoxy on the ends as the epoxy is squeezed out from around the pellets.

6. Punch end cap with reference number.

7. Pour epoxy and weigh the amount injected.

8. Target value is 5.0g. Tare scale with rigid sleeve on top but no epoxy.

9. Place surrogate rod in vise mold and put O-ring on the rod. After rod is positioned, mold will be closed by using the handle.

10. Drive the O-ring to the bottom of upper chamber by a pushing tube.

11. Inserted sleeve from bottom. O-ring is in the mold on the rod.

12. Flip and repeat step 9 to 10 for another end.

13. Final step is to clamp the mold.

\subsection{Epoxy Durability under Radiation}

Rod specimens were provided to the hot cell for a durability test of the epoxy under an irradiation environment in December 2012.

The first irradiated rod specimen SSAP25 was received in January 2013. The specimen had been sandwiched between two layers each consisting of 6 or 7 fuel rods and irradiated for about two weeks. Except colored surfaces, the exposed epoxy appeared to be intact upon the receipt from the hot-cell test. The cycle test was used in evaluating the structural integrity of epoxy under +/$300 \mathrm{~N}, 5 \mathrm{~Hz}$ (Sect. 6.2). No cracking or structural failure was seen with epoxy, even after 850 cycles when the rod was fractured. Therefore, the epoxy provided the required mechanical property and sustained the high cyclic loading.

The second irradiated SSAP rod specimen SSAP27 was received in February 2013. The specimen had been sandwiched between two layers, each consisting of 6 or 7 fuel rods and irradiated for more than six weeks. The cycle test was used in evaluating the structural integrity of epoxy under $+/-300 \mathrm{~N}, 5 \mathrm{~Hz}$ (Sec. 6.2). Again, no apparent cracking or structural failure was observed in the epoxy layer, even after 3200 cycles when the rod was fractured. Therefore, the epoxy has been proven to be capable of providing the required mechanical property for the cyclic loading.

\subsection{Adaptation of Vise Mold to Hot-Cell Test}

A meeting was held with hot-cell staff members in January 2013 on the operation and implementation of epoxy casting process in hot cell. A series of the suggestions have been provided during the meeting: 1) create removable cartridge style jaws. 2) Try WD-40 as mold release (nonstick spray option). 3) Chamfer the ends of the mold where the rigid sleeve is inserted. 4) Add stopper plates to prevent rigid sleeves from popping out of the mold. 5) Add 
extension on the drive screw for the vise. These suggestions are incorporated in the new design of vise mold as shown in Figure 11.

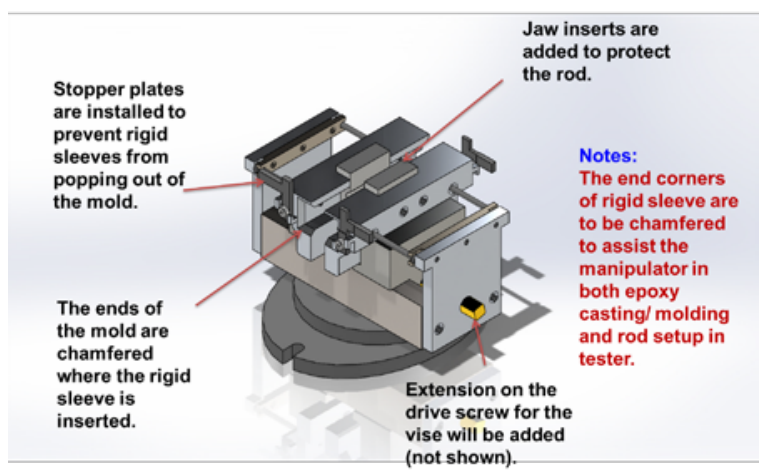

(a) Mold is open.

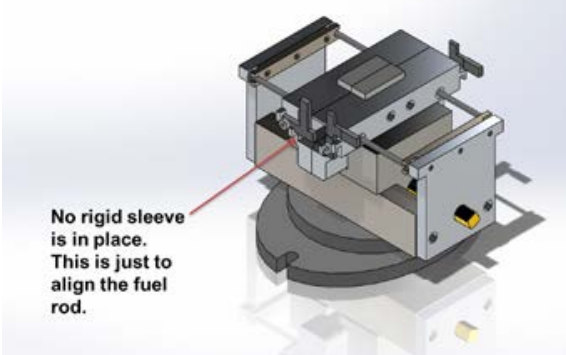

(b) Rod is inserted.

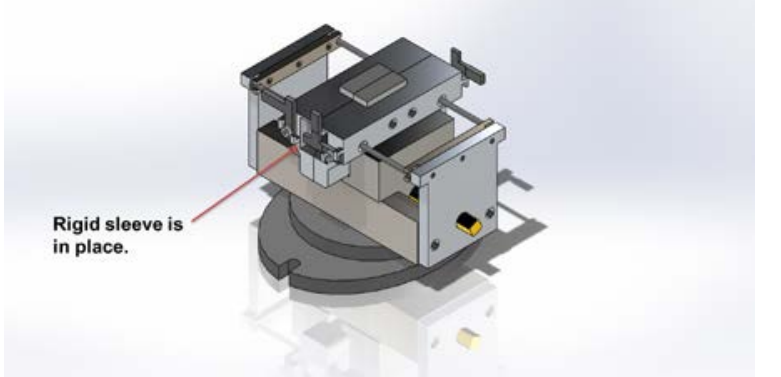

(c) Rod is in cure process.

Figure 11 Vise mold modified for hot cell test

Components for the modifications and upgrade were fabricated and reassembled February 2013, including the vise jaw, jaw inserts, rod stopper, and stopper plates. It had been observed that there was substantial plastic deformation in the polymer jaw inserts after the completion of the 
molding. The insert was designed using copper. Copper inserts were machined and received. The effect of new inserts is being reviewed. 


\section{Cycle Test under Reverse Bending}

\subsection{Summary of Tests using Surrogate Rods}

Surrogate rod made of SS (stainless steel) tube and alumina pellets are used extensively in the out-of-cell development of fatigue testing system. The specimens are labeled as SSAPxx (SS tube + Alumina pellet) and last two digits xx correspond to the specimen number. An updated summary of verification tests is given in Table 1 .

Table 1 Summary of verification tests using surrogate rods*

\begin{tabular}{|c|c|c|c|c|c|c|c|c|}
\hline Date & No & Mach & Mode & $\begin{array}{l}\mathrm{mm}, \\
\mathrm{N}^{* *}\end{array}$ & $\mathrm{~Hz}$ & $\mathrm{~N} / \mathrm{N}_{\mathrm{f}}$ & Note & $\begin{array}{l}\text { Rigid sleeve, C/P } \\
\text { epoxy bonding }\end{array}$ \\
\hline $\begin{array}{l}4 / 3,4 / 20- \\
21 / 2012\end{array}$ & 1 & MTS & $\begin{array}{l}\text { Cyc, } \\
\text { disp }\end{array}$ & 4 & 2 & $1.25 \mathrm{E}+05$ & fractured & $\begin{array}{l}\text { octagonal, teflon } \\
\text { strips, no bonding }\end{array}$ \\
\hline $4 / 24 / 2012$ & 2 & MTS & $\begin{array}{l}\text { Cyc, } \\
\text { disp }\end{array}$ & 4 & 2 & $2.62 \mathrm{E}+04$ & fractured & $\begin{array}{l}\text { octagonal, teflon } \\
\text { strips, no bonding }\end{array}$ \\
\hline $\begin{array}{l}6 / 11- \\
6 / 26 / 2012\end{array}$ & 3 & MTS & $\begin{array}{l}\text { Cyc, } \\
\text { disp }\end{array}$ & 1 & 2 & $2.00 \mathrm{E}+06$ & no fracture & $\begin{array}{l}\text { octagonal, w/o } \\
\text { teflon strip, } \\
\text { bonded }\end{array}$ \\
\hline $\begin{array}{l}6 / 28- \\
29 / 2012\end{array}$ & 4 & MTS & $\begin{array}{l}\text { Cyc, } \\
\text { disp }\end{array}$ & 2.5 & 2 & $7.25 E+04$ & fractured & $\begin{array}{l}\text { octagonal, w/o } \\
\text { teflon strip, } \\
\text { bonded }\end{array}$ \\
\hline $7 / 3-4 / 2012$ & 5 & MTS & $\begin{array}{l}\text { Cyc, } \\
\text { disp }\end{array}$ & 3 & 2 & $3.70 \mathrm{E}+04$ & $\begin{array}{l}\text { fractured } \\
\text { into halves }\end{array}$ & $\begin{array}{l}\text { octagonal, w/o } \\
\text { teflon strip, } \\
\text { bonded }\end{array}$ \\
\hline 7/9/2012 & 6 & MTS & $\begin{array}{l}\text { Cyc, } \\
\text { disp }\end{array}$ & 3.5 & 2 & $2.35 \mathrm{E}+03$ & $\begin{array}{l}\text { fractured } \\
\text { into halves }\end{array}$ & $\begin{array}{l}\text { octagonal, w/o } \\
\text { teflon strip, } \\
\text { bonded }\end{array}$ \\
\hline $\begin{array}{l}\text { 7/12- 19; } \\
\text { 8/14- } \\
21 / 2012 \\
\end{array}$ & 7 & MTS & $\begin{array}{l}\text { Cyc, } \\
\text { disp }\end{array}$ & 2 & 2 & $1.00 \mathrm{E}+06$ & no fracture & $\begin{array}{l}\text { octagonal, w/o } \\
\text { teflon strip, } \\
\text { bonded }\end{array}$ \\
\hline 8/28/2012 & 8 & MTS & $\begin{array}{l}\text { Cyc, } \\
\text { disp }\end{array}$ & 3 & 2 & $1.41 \mathrm{E}+04$ & $\begin{array}{l}\text { fractured } \\
\text { to halves }\end{array}$ & $\begin{array}{l}\text { octagonal, w/o } \\
\text { teflon strip, } \\
\text { bonded }\end{array}$ \\
\hline $\begin{array}{l}9 / 19- \\
20 / 2012\end{array}$ & 9 & MTS & $\begin{array}{l}\text { Cyc, } \\
\text { disp }\end{array}$ & 3 & 2 & $1.78 \mathrm{E}+04$ & $\begin{array}{l}\text { fractured } \\
\text { to halves }\end{array}$ & $\begin{array}{l}\text { octagonal, w/o } \\
\text { teflon strip, } \\
\text { bonded }\end{array}$ \\
\hline 9/1/2012 & 10 & Bose & $\begin{array}{l}\text { Cal, } \\
\text { load }\end{array}$ & 200 & 5 & $* * *$ & fractured & $\begin{array}{l}\text { octagonal, w/o } \\
\text { teflon strip, } \\
\text { bonded }\end{array}$ \\
\hline $\begin{array}{l}9 / 19- \\
28 / 2012\end{array}$ & 11 & Bose & $\begin{array}{l}\text { Cyc, } \\
\text { load }\end{array}$ & 200 & 5 & $6.78 \mathrm{E}+05$ & $\begin{array}{l}\text { fractured, } \\
\text { trip at - } \\
4 \mathrm{~mm}\end{array}$ & $\begin{array}{l}\text { octagonal, w/o } \\
\text { teflon strip, } \\
\text { bonded }\end{array}$ \\
\hline $\begin{array}{l}\text { 10/11- } \\
15 / 2012\end{array}$ & 12 & Bose & $\begin{array}{l}\text { Cyc, } \\
\text { load }\end{array}$ & 200 & 5 & $9.36 \mathrm{E}+05$ & $\begin{array}{l}\text { fractured, } \\
\text { trip at } \\
4 \mathrm{~mm}\end{array}$ & $\begin{array}{l}\text { octagonal, w/o } \\
\text { teflon strip, } \\
\text { bonded }\end{array}$ \\
\hline
\end{tabular}




\begin{tabular}{|c|c|c|c|c|c|c|c|c|}
\hline $\begin{array}{l}\text { 10/19- } \\
28 / 2012\end{array}$ & 13 & Bose & $\begin{array}{l}\text { Cyc, } \\
\text { load }\end{array}$ & 200 & 5 & $2.60 \mathrm{E}+06$ & no failure & $\begin{array}{l}\text { octagonal, w/o } \\
\text { teflon strip, } \\
\text { bonded }\end{array}$ \\
\hline 10/29/2012 & 131 & Bose & $\begin{array}{l}\text { Cyc, } \\
\text { load }\end{array}$ & 300 & 5 & $3.30 \mathrm{E}+03$ & $\begin{array}{l}\text { fractured, } \\
\text { from No. } \\
13\end{array}$ & $\begin{array}{l}\text { octagonal, w/o } \\
\text { teflon strip, } \\
\text { bonded }\end{array}$ \\
\hline $11 / 5 / 2012$ & 14 & Bose & $\begin{array}{l}\text { Cyc, } \\
\text { load }\end{array}$ & 250 & 5 & $1.48 \mathrm{E}+04$ & $\begin{array}{l}\text { fractured, } \\
\text { trip at - } \\
4 \mathrm{~mm}\end{array}$ & $\begin{array}{l}\text { octagonal, w/o } \\
\text { teflon strip, } \\
\text { bonded }\end{array}$ \\
\hline 11/6/2012 & 71 & Bose & $\begin{array}{l}\text { Cyc, } \\
\text { load }\end{array}$ & 250 & 5 & $2.58 \mathrm{E}+04$ & $\begin{array}{l}\text { fractured, } \\
\text { from No. } 7\end{array}$ & $\begin{array}{l}\text { octagonal, w/o } \\
\text { teflon strip, } \\
\text { bonded }\end{array}$ \\
\hline $11 / 28 / 2012$ & 15 & Bose & $\begin{array}{l}\text { Cyc, } \\
\text { load }\end{array}$ & 250 & 5 & $8.00 \mathrm{E}+03$ & $\begin{array}{l}\text { fractured, } \\
\text { trip at - } \\
4 \mathrm{~mm}\end{array}$ & $\begin{array}{l}\text { octagonal, w/o } \\
\text { teflon strip, } \\
\text { bonded }\end{array}$ \\
\hline 11/30/2012 & 16 & Bose & $\begin{array}{l}\text { Cyc, } \\
\text { load }\end{array}$ & 300 & 5 & $2.50 \mathrm{E}+03$ & $\begin{array}{l}\text { fractured, } \\
\text { trip at }(+/-) \\
4 \mathrm{~mm}\end{array}$ & $\begin{array}{l}\text { octagonal, w/o } \\
\text { teflon strip, } \\
\text { bonded }\end{array}$ \\
\hline $12 / 3 / 2012$ & 17 & Bose & $\begin{array}{l}\text { Cyc, } \\
\text { load }\end{array}$ & 300 & 5 & $1.79 \mathrm{E}+03$ & $\begin{array}{l}\text { broken to } \\
\text { halves, } \\
\text { demo for } \\
\text { NRC }\end{array}$ & $\begin{array}{l}\text { octagonal, w/o } \\
\text { teflon strip, } \\
\text { bonded }\end{array}$ \\
\hline $12 / 13 / 2012$ & 18 & Bose & $\begin{array}{l}\text { Mon, } \\
\text { disp }\end{array}$ & 16 & 0.2 & $1.00 \mathrm{E}+00$ & & $\begin{array}{l}\text { octagonal, w/o } \\
\text { teflon strip, } \\
\text { bonded }\end{array}$ \\
\hline $12 / 14 / 2012$ & 19 & Bose & $\begin{array}{l}\text { Mon, } \\
\text { disp }\end{array}$ & 20 & 0.2 & $1.00 \mathrm{E}+00$ & & $\begin{array}{l}\text { octagonal, w/o } \\
\text { teflon strip, } \\
\text { bonded }\end{array}$ \\
\hline $12 / 17 / 2012$ & 20 & Bose & $\begin{array}{l}\text { Mon, } \\
\text { disp }\end{array}$ & 20 & 0.2 & $1.00 \mathrm{E}+00$ & & $\begin{array}{l}\text { octagonal, w/o } \\
\text { teflon strip, } \\
\text { bonded }\end{array}$ \\
\hline $\begin{array}{l}12 / 19- \\
1 / 6 / 2013\end{array}$ & 21 & Bose & $\begin{array}{l}\text { Cyc, } \\
\text { load }\end{array}$ & 200 & 5 & $4.20 \mathrm{E}+06$ & no failure & $\begin{array}{l}\text { octagonal, w/ } \\
\text { graphene strip, } \\
\text { bonded }\end{array}$ \\
\hline $1 / 7 / 2013$ & 23 & Bose & $\begin{array}{l}\text { Cyc, } \\
\text { load }\end{array}$ & 250 & 5 & $1.96 \mathrm{E}+04$ & $\begin{array}{l}\text { fractured, } \\
\text { trip at } \\
4 \mathrm{~mm}\end{array}$ & $\begin{array}{l}\text { octagonal, w/o } \\
\text { teflon strip, } \\
\text { bonded }\end{array}$ \\
\hline $1 / 7 / 2013$ & 24 & Bose & $\begin{array}{l}\text { Cyc, } \\
\text { load }\end{array}$ & 300 & 5 & $2.95 \mathrm{E}+03$ & $\begin{array}{l}\text { fractured } \\
\text { near r.s., } \\
\text { trip at } 4 \\
\text { mm }\end{array}$ & $\begin{array}{l}\text { octagonal, w/o } \\
\text { teflon strip, } \\
\text { bonded }\end{array}$ \\
\hline $1 / 8 / 2013$ & 25 & Bose & $\begin{array}{l}\text { Cyc, } \\
\text { load }\end{array}$ & 300 & 5 & $8.56 \mathrm{E}+02$ & $\begin{array}{l}\text { trip at }-4 \\
\text { mm }\end{array}$ & $\begin{array}{l}\text { irradiated, } \\
\text { octagonal, w/o } \\
\text { teflon strip, } \\
\text { bonded }\end{array}$ \\
\hline 1/8- & 26 & Bose & Сус, & 200 & 5 & $8.50 \mathrm{E}+06$ & fractured, & octagonal, w/o \\
\hline
\end{tabular}




\begin{tabular}{|c|c|c|c|c|c|c|c|c|}
\hline 3/18/2013 & & & load & & & & $\begin{array}{l}\text { trip at } \\
\text { 4mm }\end{array}$ & $\begin{array}{l}\text { teflon strip, } \\
\text { bonded }\end{array}$ \\
\hline $1 / 29 / 2013$ & 27 & Bose & $\begin{array}{l}\text { Cyc, } \\
\text { load }\end{array}$ & 300 & 5 & $2.20 \mathrm{E}+03$ & $\begin{array}{l}\text { broke into } \\
\text { halves }\end{array}$ & $\begin{array}{l}\text { irradiated, } \\
\text { octagonal, w/o } \\
\text { teflon strip, } \\
\text { bonded }\end{array}$ \\
\hline $2 / 14 / 2013$ & 28 & MTS & $\begin{array}{l}\text { Cyc, } \\
\text { load }\end{array}$ & 250 & 2 & $2.85 \mathrm{E}+04$ & $\begin{array}{l}\text { distorted, } \\
\mathrm{z} 0=58.76, \\
\text { trip at } 70\end{array}$ & $\begin{array}{l}\text { octagonal, w/o } \\
\text { teflon strip, } \\
\text { bonded }\end{array}$ \\
\hline 2/18/2013 & 29 & MTS & $\begin{array}{l}\text { Cyc, } \\
\text { load }\end{array}$ & 250 & 2 & $2.10 \mathrm{E}+04$ & $\begin{array}{l}\text { fractured, } \\
\mathrm{z} 0=58.76, \\
\text { trip at } 50\end{array}$ & $\begin{array}{l}\text { octagonal, w/o } \\
\text { teflon strip, } \\
\text { bonded }\end{array}$ \\
\hline 2/20/2013 & 30 & MTS & $\begin{array}{l}\text { Cyc, } \\
\text { load }\end{array}$ & 250 & 2 & $4.85 \mathrm{E}+04$ & $\begin{array}{l}\text { fractured, } \\
\mathrm{z} 0=58.76, \\
\text { trip at } 70\end{array}$ & $\begin{array}{l}\text { octagonal 440C } \\
\text { w/o teflon strip, } \\
\text { bonded }\end{array}$ \\
\hline 2/21/2013 & 31 & MTS & $\begin{array}{l}\text { Cyc, } \\
\text { load }\end{array}$ & 300 & 2 & $2.25 \mathrm{E}+03$ & $\begin{array}{l}\text { fractured, } \\
\mathrm{z} 0=58.76, \\
\text { trip at } 50.8\end{array}$ & $\begin{array}{l}\text { octagonal, w/o } \\
\text { teflon strip, } \\
\text { bonded }\end{array}$ \\
\hline $2 / 22 / 2013$ & 32 & MTS & $\begin{array}{l}\text { Cyc, } \\
\text { load }\end{array}$ & 300 & 2 & $1.25 \mathrm{E}+03$ & $\begin{array}{l}\text { fractured, } \\
\mathrm{z} 0=58.96, \\
\text { trip at } 51\end{array}$ & $\begin{array}{l}\text { octagonal, w/o } \\
\text { teflon strip, } \\
\text { bonded }\end{array}$ \\
\hline $2 / 25 / 2013$ & 33 & MTS & $\begin{array}{l}\text { Cyc, } \\
\text { load }\end{array}$ & 300 & 2 & $4.13 \mathrm{E}+03$ & $\begin{array}{l}\text { fractured, } \\
\mathrm{z} 0=58.96, \\
\text { trip at } 50.8\end{array}$ & $\begin{array}{l}\text { octagonal 440C, } \\
\text { w/o teflon strip, } \\
\text { bonded }\end{array}$ \\
\hline $2 / 26 / 2013$ & 35 & MTS & $\begin{array}{l}\text { Cyc, } \\
\text { load }\end{array}$ & 200 & 2 & $1.11 \mathrm{E}+06$ & no failure & $\begin{array}{l}\text { octagonal, w/o } \\
\text { teflon strip, } \\
\text { bonded }\end{array}$ \\
\hline $\begin{array}{l}3 / 6- \\
3 / 18 / 2013\end{array}$ & 36 & MTS & $\begin{array}{l}\text { Cyc, } \\
\text { load }\end{array}$ & 200 & 2 & $3.11 \mathrm{E}+06$ & $\begin{array}{l}\text { Stopped } \\
\text { for oil } \\
\text { change on } \\
3-25-2013\end{array}$ & $\begin{array}{l}\text { octagonal } 440 \mathrm{C} \text {, } \\
\text { w/o teflon strip, } \\
\text { bonded }\end{array}$ \\
\hline
\end{tabular}

* Surrogate rods have a length of 6" and are made of SS tube (ID $0.382 "$ or $11.07 \mathrm{~mm}$, OD 0.436 " or $9.70 \mathrm{~mm}$ ) and ten alumina pellets $(\phi 0.375$ ” or $9.525 \mathrm{~mm}$, and length of 0.598 ” or $15.2 \mathrm{~mm})$.

** +/- amplitude for cycle tests; peak value for monotonic tests; $\mathrm{mm}$ is for displacement control and $\mathrm{N}$ is for load control.

*** SSAP10 was used in the calibration of Bose system and no cycle number was tracked.

\subsection{Cycle Test under Load Control}

The verification test using surrogate rods made of SS cladding and alumina pellets on Bose machines was started in October 2012. The under load through Cycle Indirect along with the 
pinning of U-frame setup is used. Subsequent cycle tests using SSAP11, SSAP12, and SSAP13 were conducted under $5 \mathrm{~Hz}, \pm 200 \mathrm{~N}$. The output indicated a quite consistent load level during all of the cycle tests. The former two tests generated lifetimes of $678 \mathrm{~K}$ and 936 cycles with about 40 to $42 \%$ drop of flexural rigidity before fractures. The fractures all occurred within the gage sections and the specimen hold areas appeared to be fine. The last specimen was still working with about only $11 \%$ drop of rigidity after more $1.7 \mathrm{M}$ cycles. The observed difference in lifetimes was perhaps due to the compositions and machining of specimen that came from a different batch of preparation.

The amplitude was then raised to $+/-250$ and $+/-300 \mathrm{~N}$ with on-line monitoring enabled. The lifetime obtained under load control is shown in Figure 12 as a function of cycles. The lifetime of the surrogate rods is shown to be similar to that of the surrogate rods obtained at equivalent strain levels under displacement control (Wang et al., 2012). ${ }^{3,6}$

The variation of curvature and flexural rigidity are demonstrated in the following figures along with the monitoring of moment applied, ${ }^{7}$ Figure 13 to Figure 25.

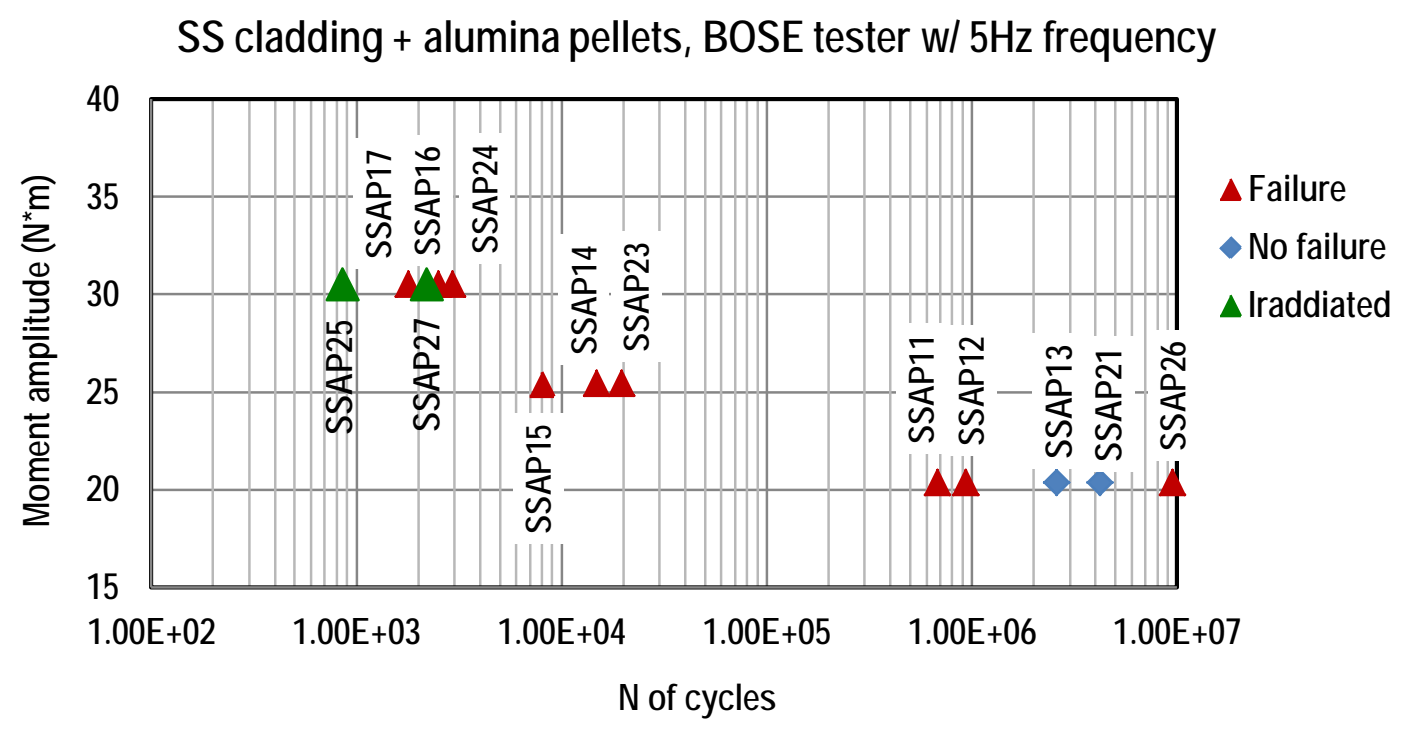

Figure 12 Moment as a function of cycles or cycles to fail. No failure was observed for SSAP13, SSAP21. The SSAP26 was failed $\sim 1 \times 10^{7}$ cycles, where $5.4 \mathrm{M}$ is carried out at $10 \mathrm{~Hz}$. SSAP25 was irradiated 2 weeks under a sandwich configuration between 6- and 7-fuel rod layers. SSAP27 irradiated 4 weeks. 


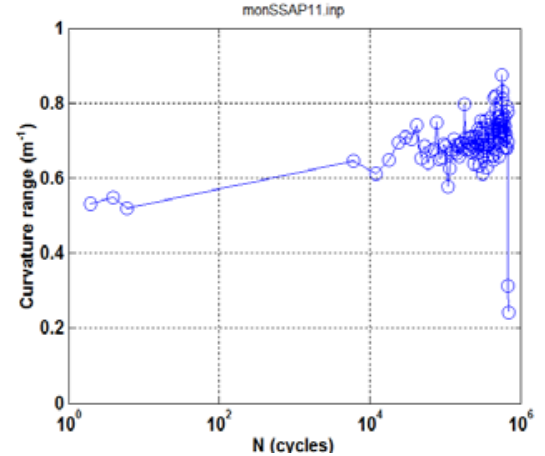

(a)

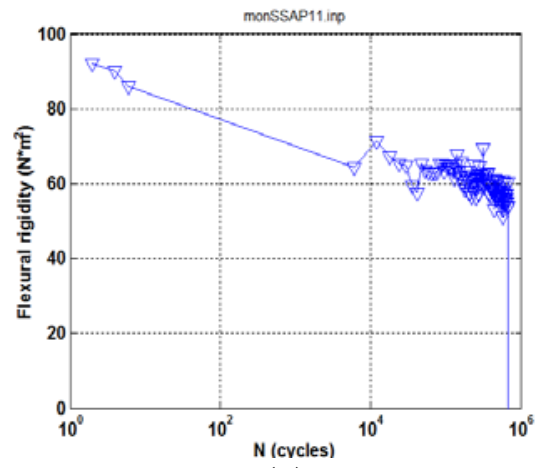

(c)

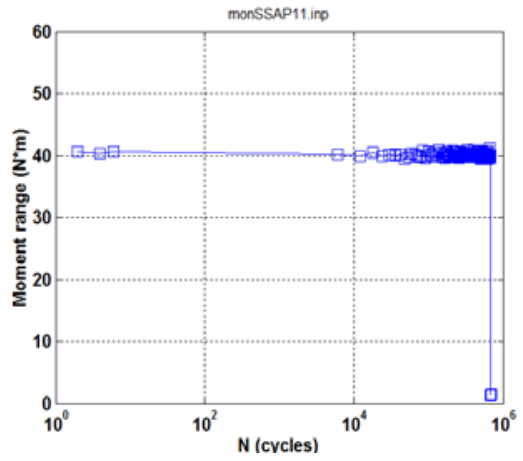

(b)

Figure 13 Variation of (a) curvature, (b) moment, and (c) rigidity based on on-line monitoring of SSAP11: \pm 200 mm, 5 Hz.

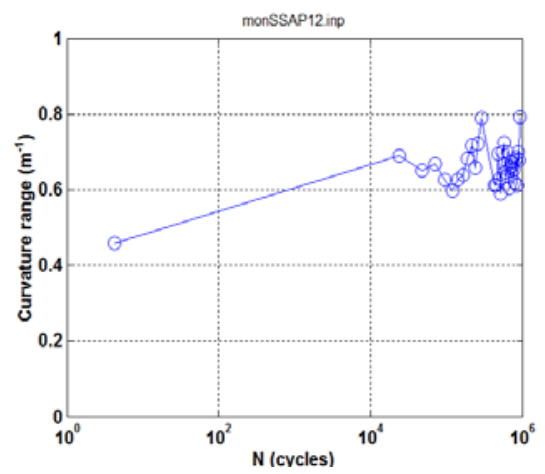

(a)

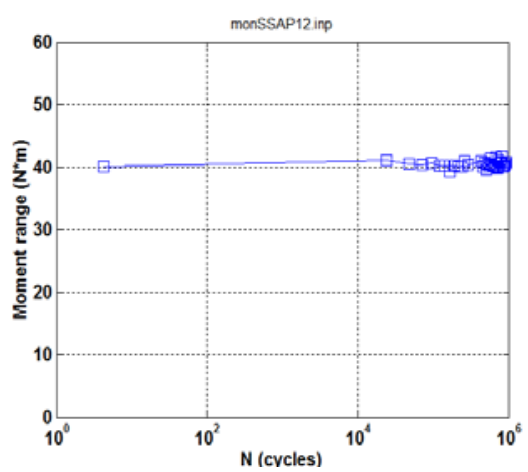

(b) 


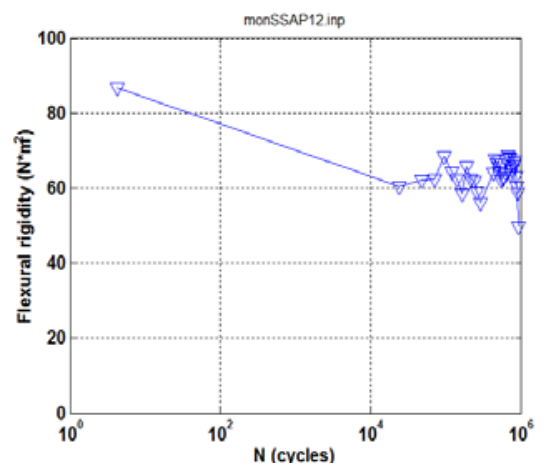

(c)

Figure 14 Variation of (a) curvature, (b) moment, and (c) rigidity based on on-line monitoring of SSAP12: $\pm 200 \mathrm{~mm}, 5 \mathrm{~Hz}$.

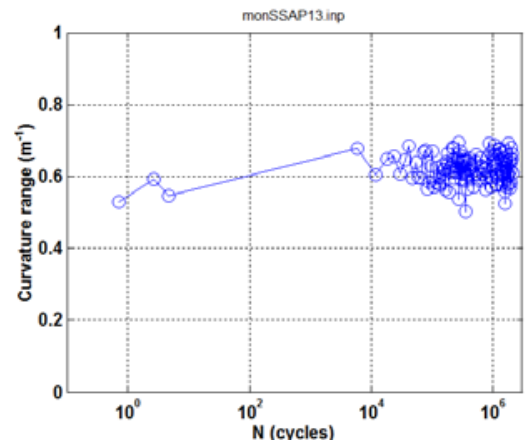

(a)

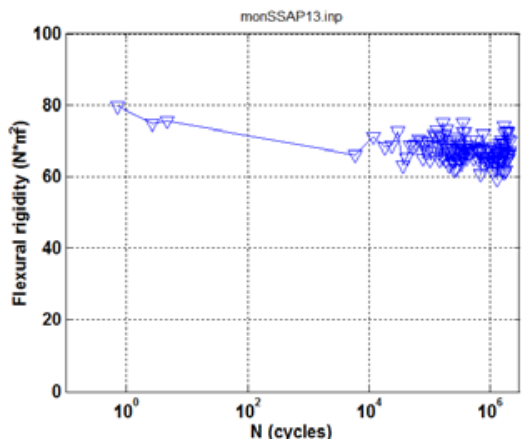

(c)

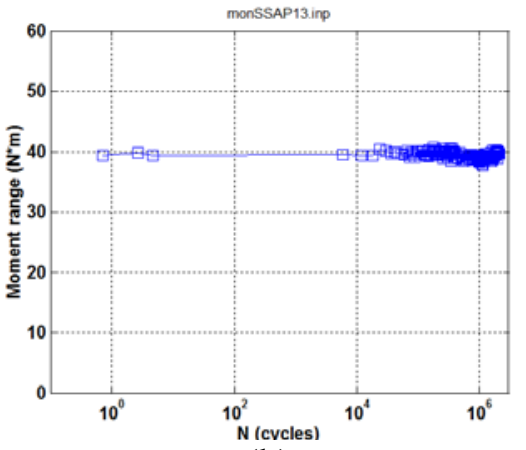

(b)

Figure 15 Variation of (a) curvature, (b) moment, and (c) rigidity based on on-line monitoring of SSAP13: $\pm 200 \mathrm{~mm}, 5 \mathrm{~Hz}$. 


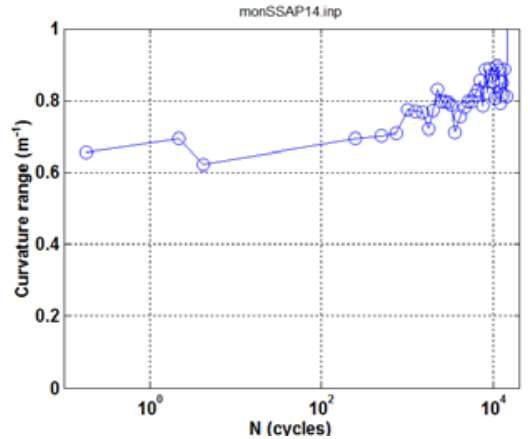

(a)

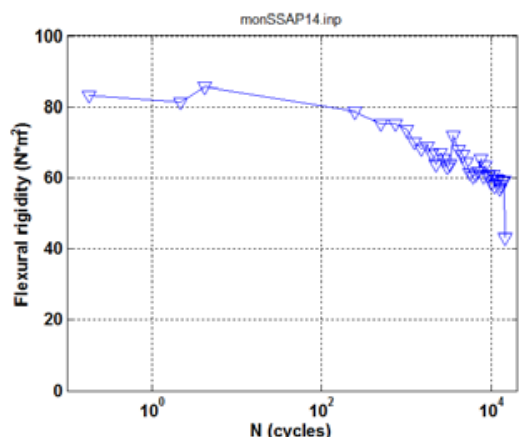

(c)

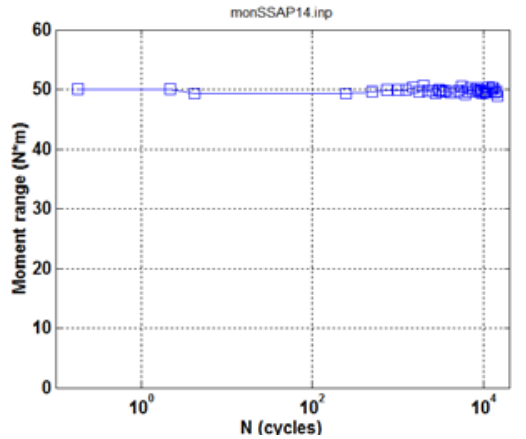

(b)

Figure 16 Variation of (a) curvature, (b) moment, and (c) rigidity based on on-line monitoring of SSAP14: $\pm 250 \mathrm{~mm}, 5 \mathrm{~Hz}$.

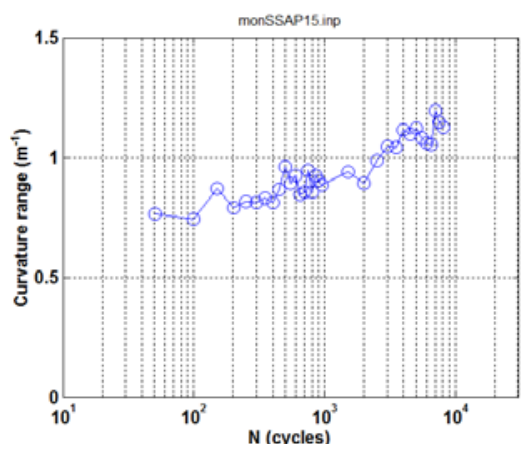

(a)

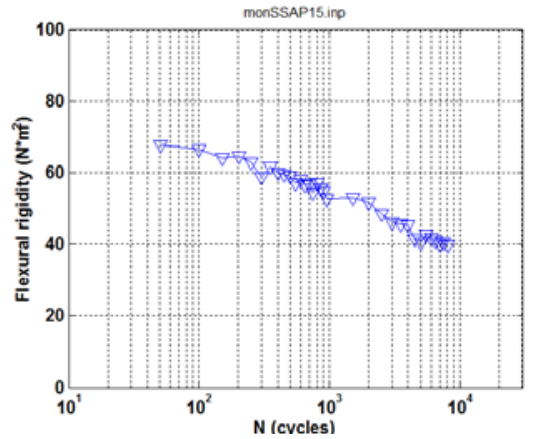

(c)

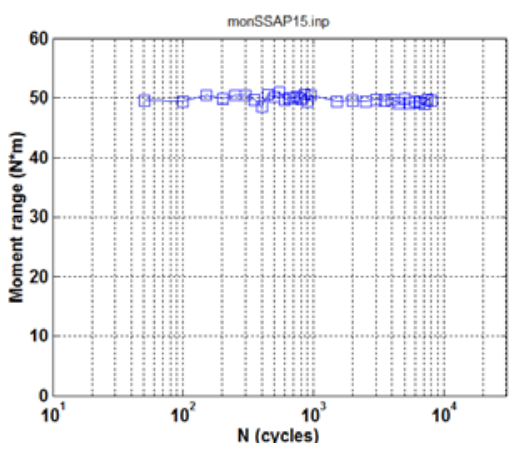

(b) 
Figure 17 Variation of (a) curvature, (b) moment, and (c) rigidity based on on-line monitoring of SSAP15: $\pm 250 \mathrm{~mm}, 5 \mathrm{~Hz}$.

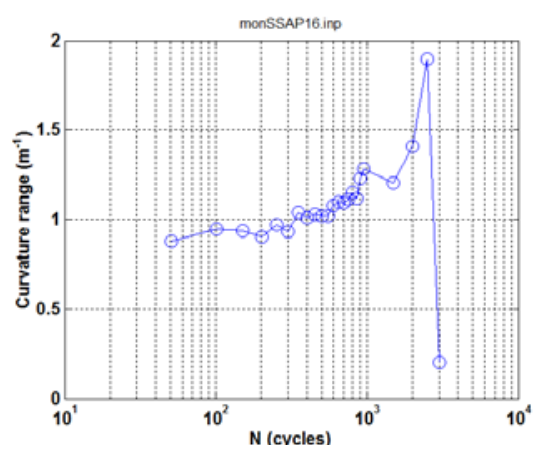

(a)

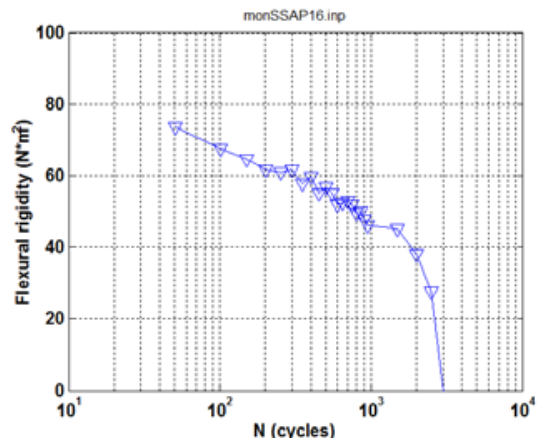

(c)

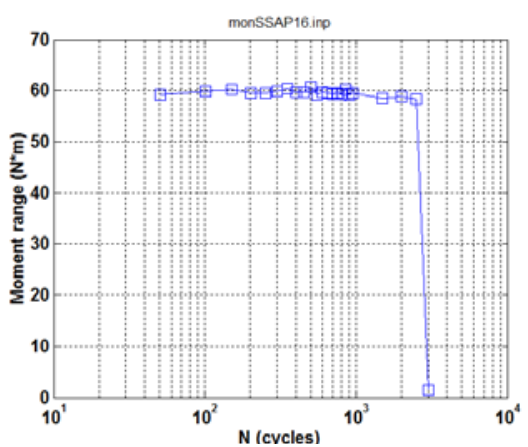

(b)

Figure 18 Variation of (a) curvature, (b) moment, and (c) rigidity based on on-line monitoring of SSAP16: $\pm 300 \mathrm{~mm}, 5 \mathrm{~Hz}$.

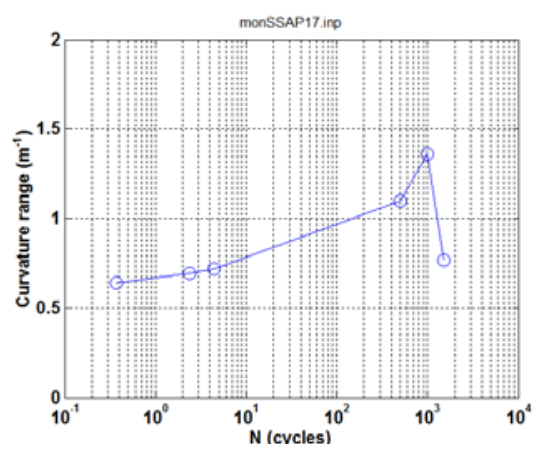

(a)

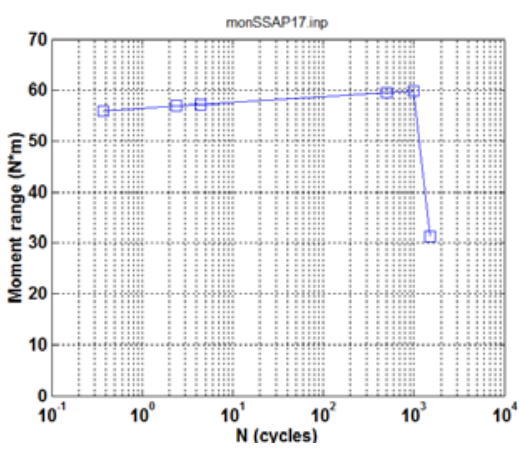

(b) 


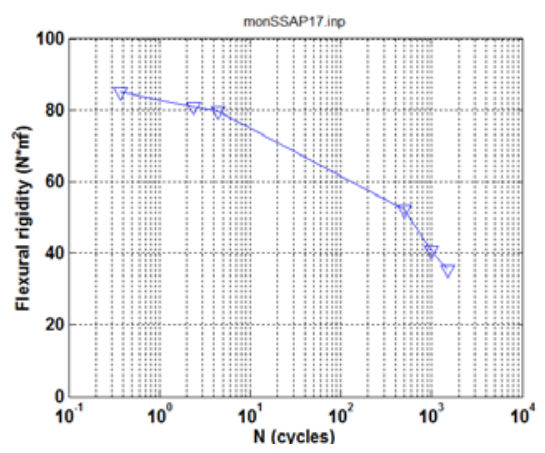

(c)

Figure 19 Variation of (a) curvature, (b) moment, and (c) rigidity based on on-line monitoring of SSAP17: $\pm 300 \mathrm{~mm}, 5 \mathrm{~Hz}$.

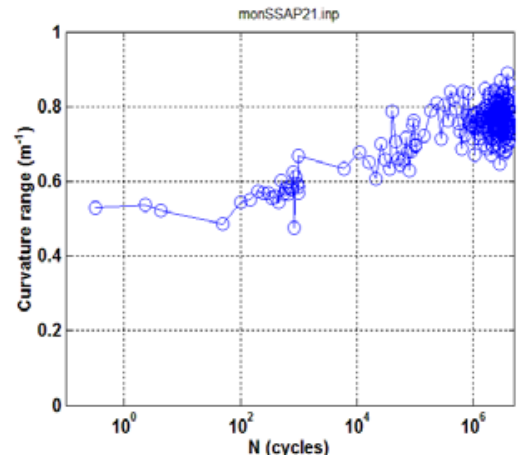

(a)

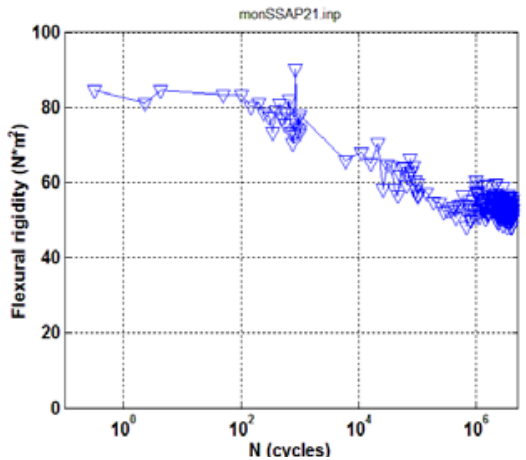

(c)

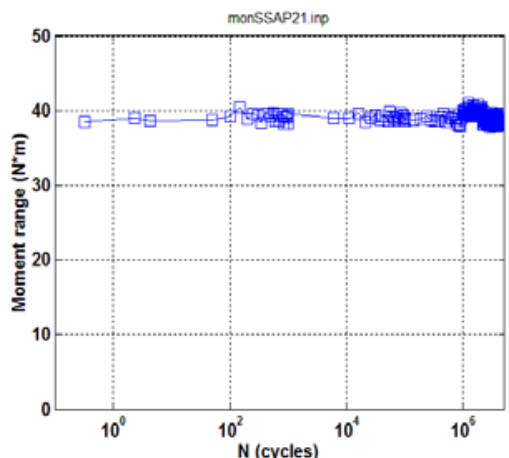

(b)

Figure 20 Variation of (a) curvature, (b) moment, and (c) rigidity based on on-line monitoring of SSAP21: $\pm 200 \mathrm{~mm}, 5 \mathrm{~Hz}$. 


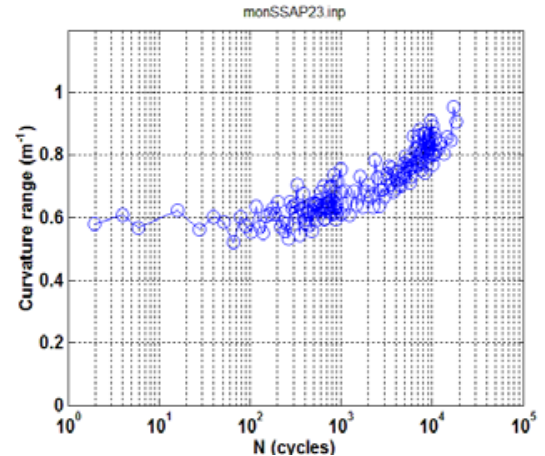

(a)

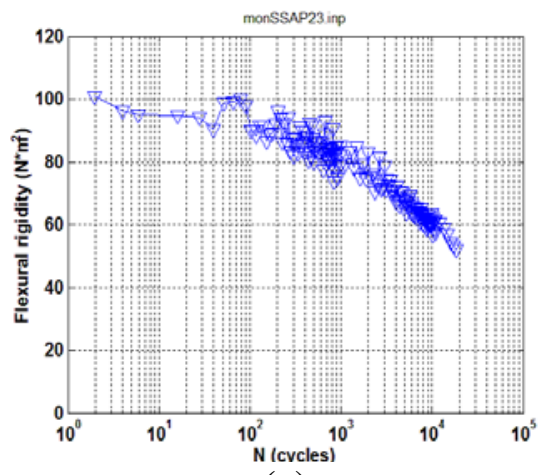

(c)

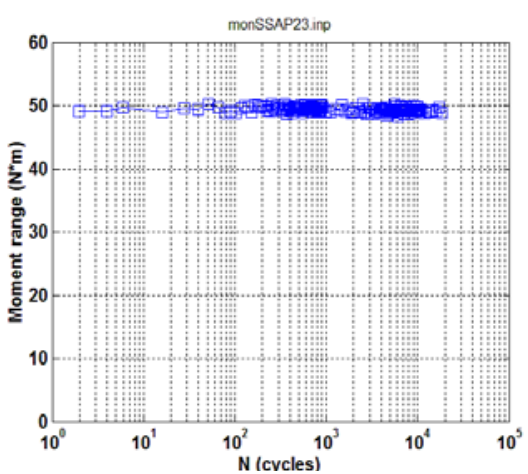

(b)

Figure 21 Variation of (a) curvature, (b) moment, and (c) rigidity based on on-line monitoring of SSAP23: $\pm 250 \mathrm{~mm}, 5 \mathrm{~Hz}$.

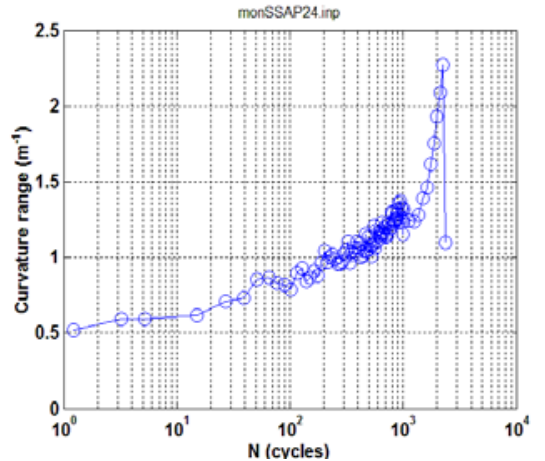

(a)

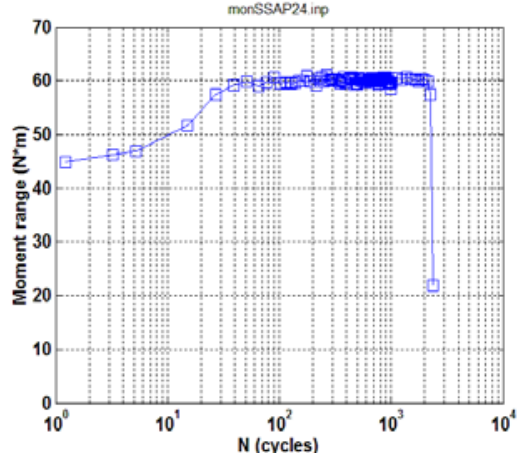

(b) 


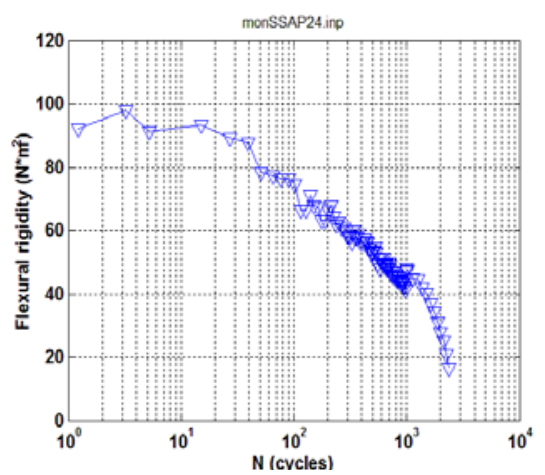

(c)

Figure 22 Variation of (a) curvature, (b) moment, and (c) rigidity based on on-line monitoring of SSAP24: \pm 300 mm, 5 Hz.

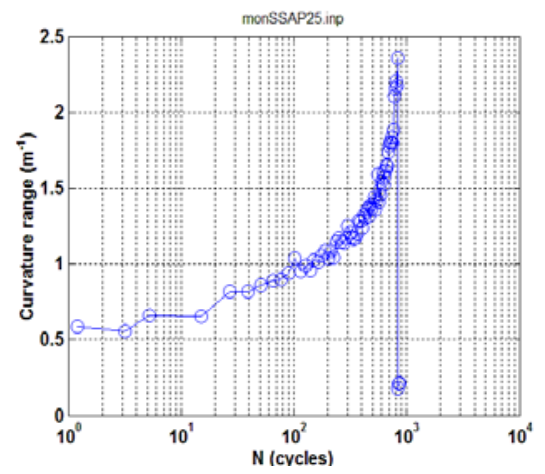

(a)

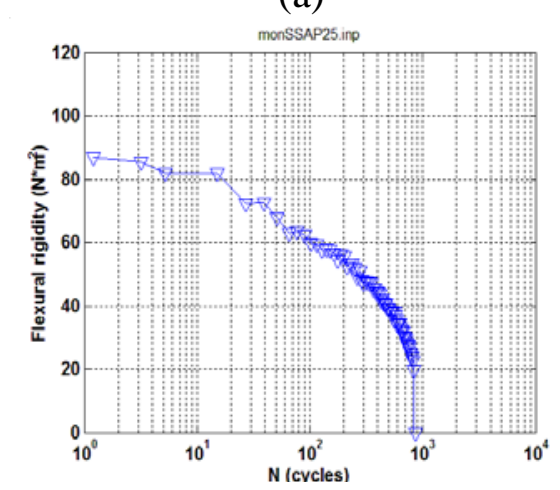

(c)

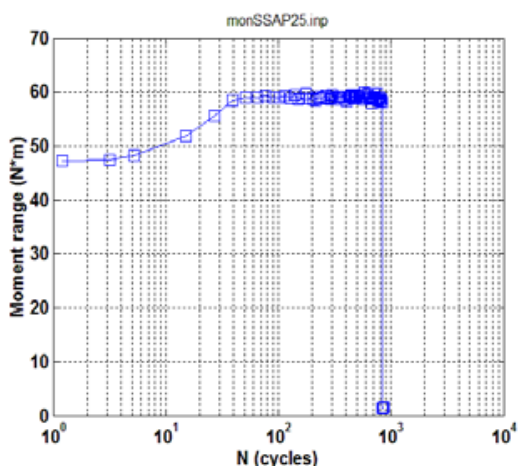

(b) 


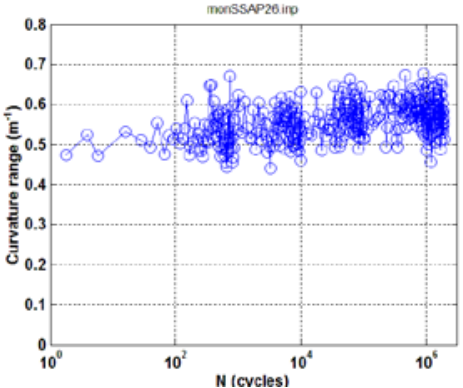

(a)

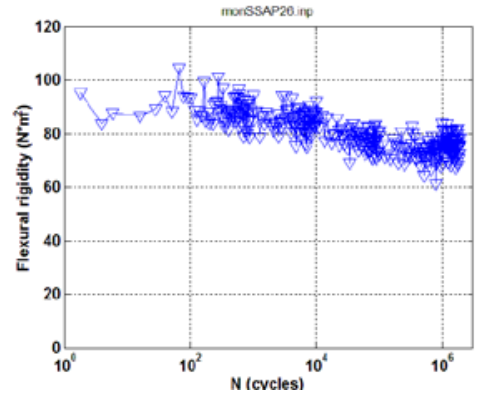

(c)

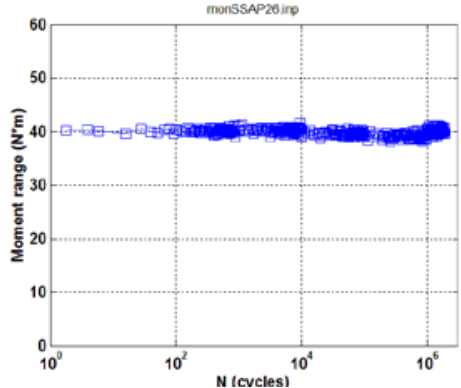

(b)

Figure 24 Variation of (a) curvature, (b) moment, and (c) rigidity based on on-line monitoring of SSAP26: $\pm 200 \mathrm{~mm}, 5 \mathrm{~Hz}$.

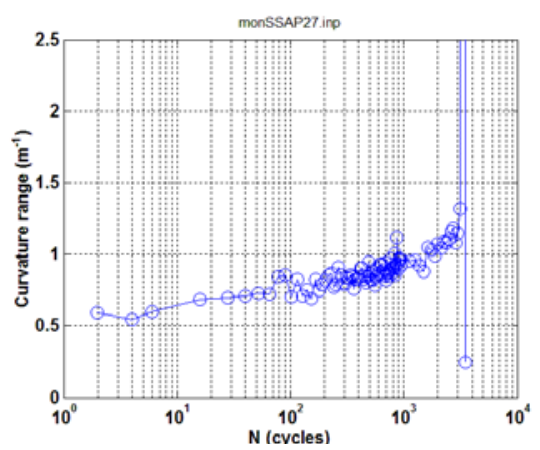

(a)

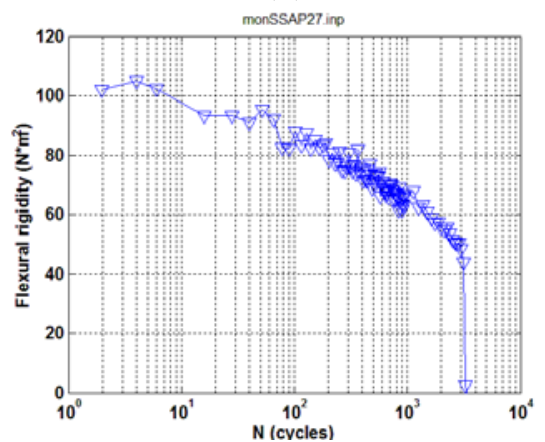

(c)

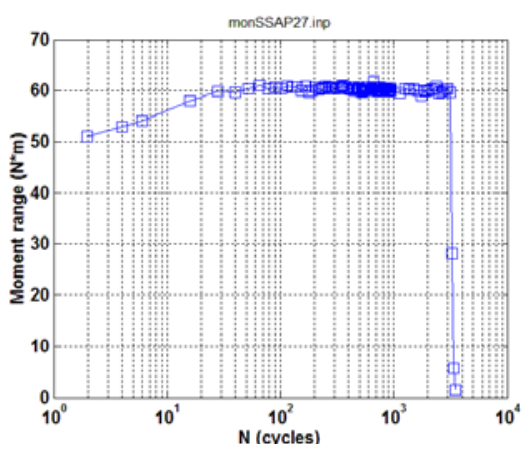

(b) 
Figure 25 Variation of (a) curvature, (b) moment, and (c) rigidity based on on-line monitoring of SSAP27: $\pm 300 \mathrm{~mm}, 5 \mathrm{~Hz}$.

\subsection{Cycle Test Procedure}

Cycle test under load control on Bose machine is generally conducted through the following procedure. A load condition of $+/-200 \mathrm{~N}, 10 \mathrm{~Hz}, 1000000$ cycles is used for demonstration.

1. Prepare Bose machine:

1) Turn on the power modules.

2) Turn on the PCI box along RDP power supply for 30 minutes.

2. Install the rod specimen.

1) Turn the specimen spring away from the opening.

2) Unscrew the bolts on the end blocks of rigid arm.

3) Insert the specimen from the lateral side.

4) Turn back the specimen spring to secure the specimen from end

5) Tighten the two end blacks using $10 \mathrm{lb}$-in wrench.

6) Put the LVDT clamp back onto the rod.

3. Prepare WinTest7

1) Set channel limits: disp $1 \& 2+/-4 \mathrm{~mm}$; load $1 \& 2+/-1000 \mathrm{~N}$

2) Reset channels: disp 1 ->tare; load 1 -> tare; disp 2 ->tare; load 2 -> tare; LVDT1 -> tare; LVDT2 -> tare; LVDT3 -> tare;

3) Tuning Axial 1 under displacement control

a. Axial 1: sine $->+/-1.0 \mathrm{~mm}, 10 \mathrm{~Hz},->$ TunIQ

4) Tuning Axial 2 under displacement control

a. Axial 2: sine ->+/-1.0mm, 10Hz, -> TunIQ

5) Waveform definition Axial 1:

a. Axial 1: block -> cycle indirect ->disp1 +/-0.7mm -> load1 +/-200N, -> $10 \mathrm{~Hz}->$ cycle $1,000,000$

b. Data acquire: 0.2 seconds/scan, 200 point/scan, 81 scans, 1250 seconds for interval

c. Time domain data: SSAP39 -> test012

6) Waveform definition Axial 2: block -> cycle indirect ->disp1 +/-0.7mm -> load1 +/$200 \mathrm{~N},->10 \mathrm{~Hz}$-> cycle $1,000,000$

7) Optional: Save the test file for future use.

8) Axial $1 \& 2$ Power on

4. Start test

1) Check if the target load $+/-200 \mathrm{~N}$ has been reached using scope. 


\section{Bending Testing under Monotonic Loading}

Three static tests of SSAP surrogate rods were conducted as a part of the proof of methodology test plan. The displacement control with a loading rate of $0.2 \mathrm{~mm} / \mathrm{s}$ was used. The maximum displacement was $16 \mathrm{~mm}$ for the first test and $20 \mathrm{~mm}$ for other two. The latter reached $79 \%$ of the displacement capacity of the system. Generally, the results are repeatable as seen in Figure 26. The initial linear range was quite short as expected. It has been shown from the momentcurvature relation that the apparent yielding range is located between 20 to $35 \mathrm{~N} * \mathrm{~m}$. For the amplitudes of 20 to $30 \mathrm{N*m}$ used in the verification tests, it can be seen that the current cyclic bending tests (Sect. 6.2; Sect. 9) actually cover the major part of the earlier yielding stage. At the same time, the local fluctuations were also observed on the moment-curvature curve, but they could hardly be related to any micro process within the rod.

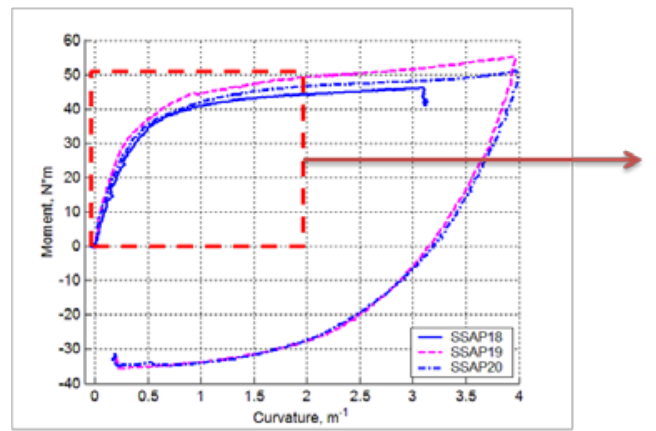

- Linear stage of momentcurvature curve appears to be very short.

- Local fluctuations were seen, but hardly related to micro processes.

- Instantaneous flexural rigidity varies greatly in beginning.
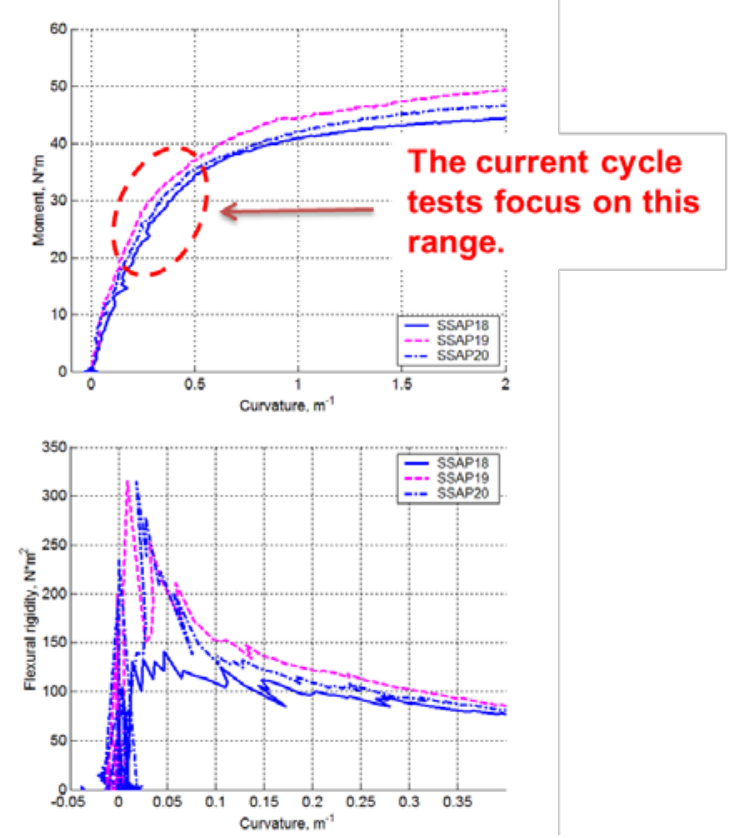

Figure 26 Three static bending tests were completed w/ max disp. of $20 \mathrm{~mm}$ at loading points of U-frame setup. 


\section{Uniaxial Tensile Test of SS Tube}

Two SS 304 tubes were tested as a part of the proof of methodology test plan and results are given in Figure 27 and Figure 28. The tubes had a nominal ID 0.381, OD 0.437”, and gage length 1.625". Tests were conducted in hydraulic testing machines with an extensometer mounted to monitor the displacement over the gage length of the specimens. The obtained Young's modulus was 176 to $195 \mathrm{GPa}$, YS (yield stress) at $0.2 \%$ offset was 292 to $325 \mathrm{MPa}$, and UTS (ultimate tensile strength) was $664 \mathrm{MPa}$. These values are close to those provided by the data sheet (193 GPa Young's modulus, 292 MPa YS at 0.2\% offset and 621MPa UTS). These results are consistent with the datasheet of SS 304 manufacturer (AK Steel, 2007). ${ }^{8}$ The Young's modulus value of SS04 is a little lower than that of datasheet, which is probably attributed to the variation of tube thickness and the effect of machining.

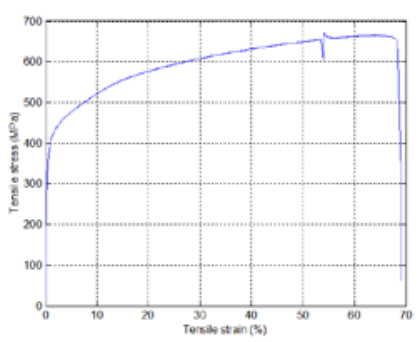

(a)

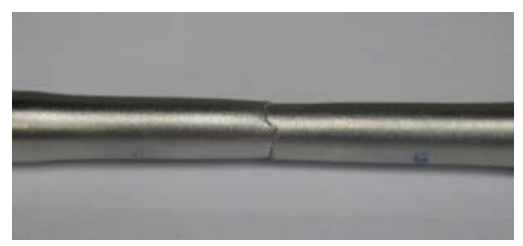

(c)

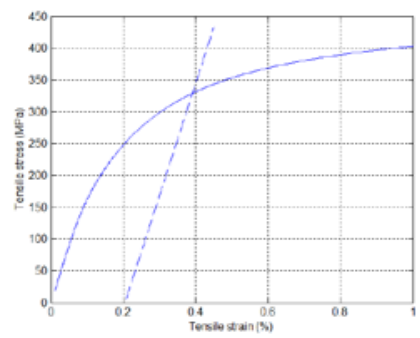

(b)

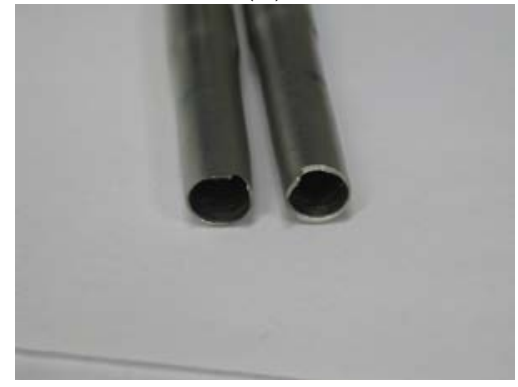

(d)

Figure 27 Uniaxial tensile test results: (a) strain - stress curve, (b) initial part of strain-stress curve, (c) failed specimens and (d) fracture surface. SS04, OD 0.4375”, ID 0.3815, GL 1.625”; E = 176 GPa; YS at $0.2 \%$ offset $=325 \mathrm{MPa}$; UTS $=664 \mathrm{MPa}$ 


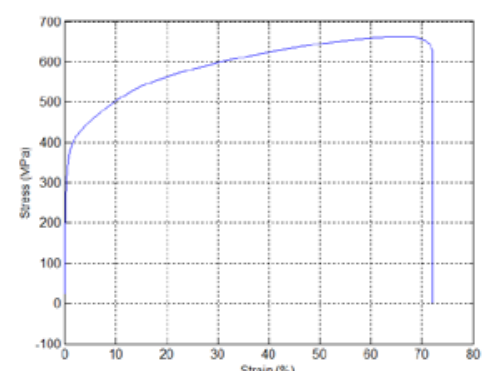

(a)

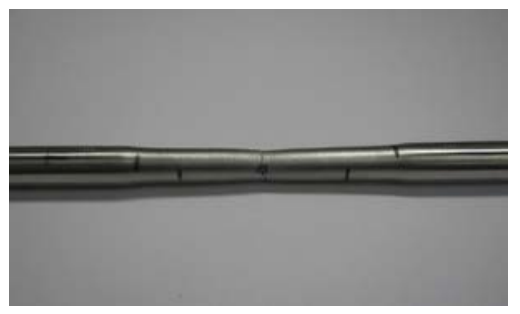

(c)

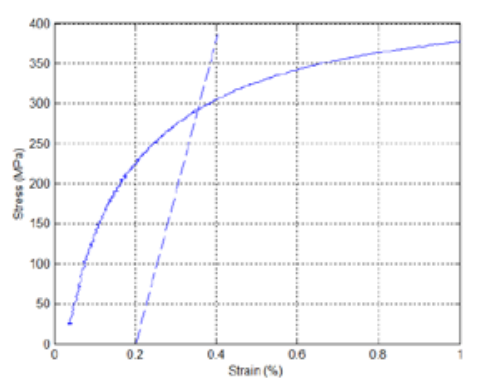

(b)

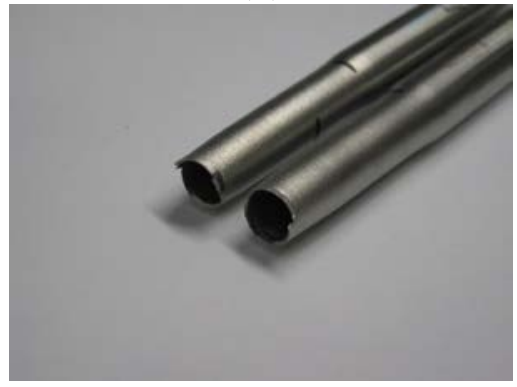

(d)

Figure 28 Uniaxial tensile test results: (a) strain - stress curve, (b) initial part of strain-stress curve, (c) failed specimens and (d) fracture surface. SS05 (SS-MOX-02); OD 0.4365”, ID 0.381”, 1.625” GL; E = $195 \mathrm{GPa}$; YS at $0.2 \%$ offset $=292 \mathrm{MPa}$; UTS $=664 \mathrm{MPa}$. 


\section{Verification Cycle Test using MTS Machine}

The cycle testing on MTS hydraulic testing machines was started in order to verify the results obtained on the Bose machine. The objective of this activity is to complete a test matrix with three loads each with three test tests.

The cycle tests were conducted under load control using $2 \mathrm{~Hz}$, and the part of results are summarized in Figure 29. In general, the results based on the tests on MTS machine agree with those on Bose machine (Figure 12). The variation of curvature and flexural rigidity are demonstrated in the following figures along with the monitoring of moment applied, Figure 30 to Figure 37.

Dynamic testing using the MTS hydraulic testing machine was stopped due to due to the maintenance requirements on oil change, and hose replacement of the testing machining. The resume of the cycle tests on MTS machine depends on the availability of funding for the oil change and the hose replacement.

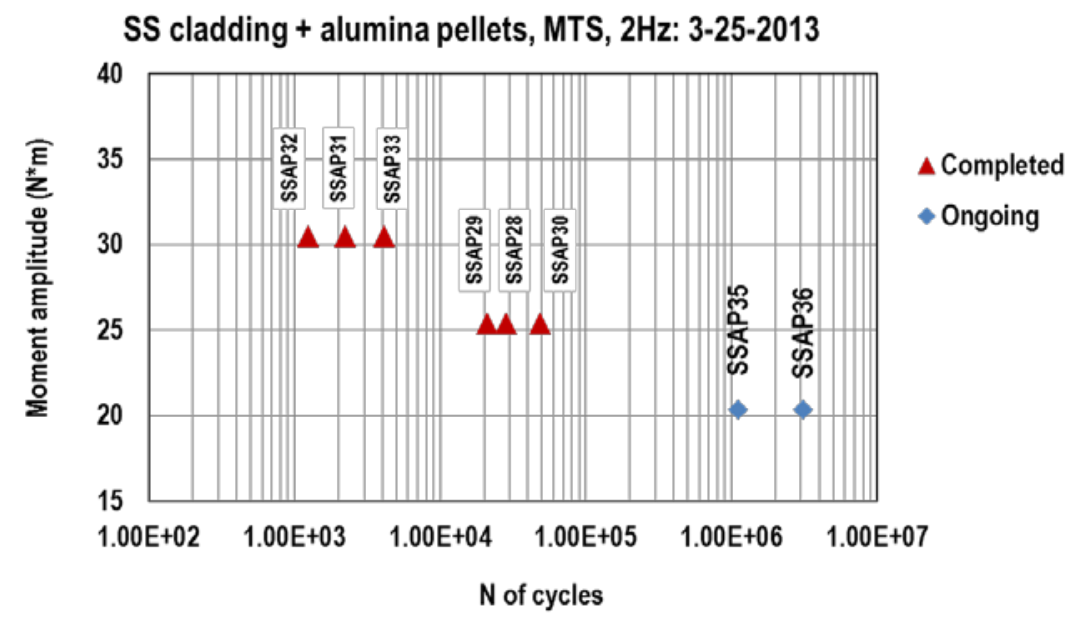

Figure 29 Moment as a function of cycles or cycles to fail. SSAP30, SSAP33 and SSAP36 had 440C hardened rigid sleeves; SSAP35 is held off for SSAP36 for hardened rigid sleeve verification testing. 


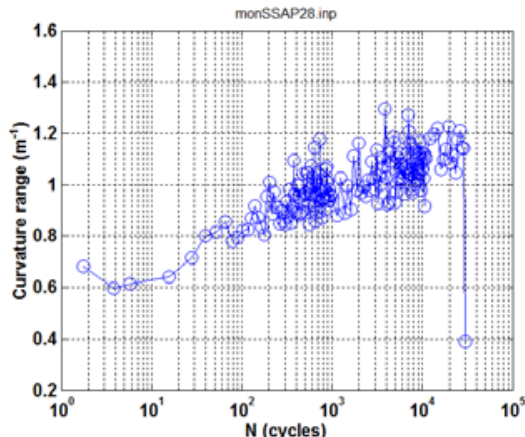

(a)

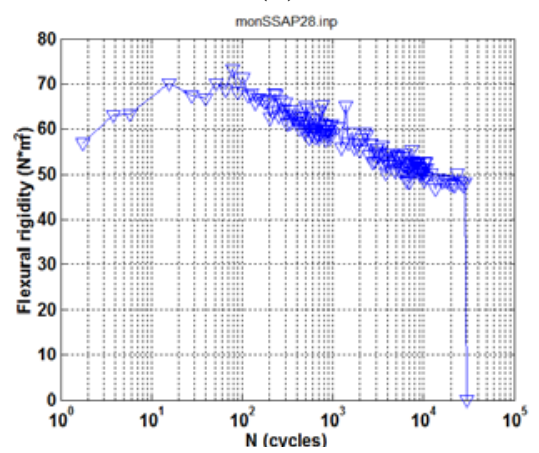

(c)

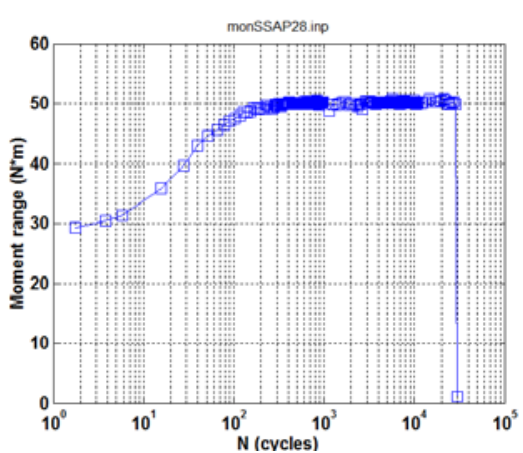

(b)

Figure 30 Variation of (a) curvature, (b) moment, and (c) rigidity based on on-line monitoring of SSAP28: $\pm 250 \mathrm{~mm}, 2 \mathrm{~Hz}$.

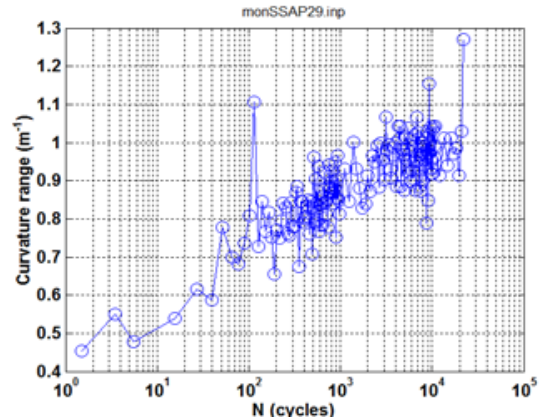

(a)

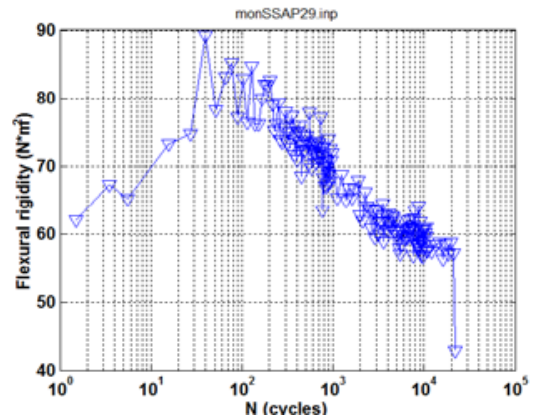

(c)

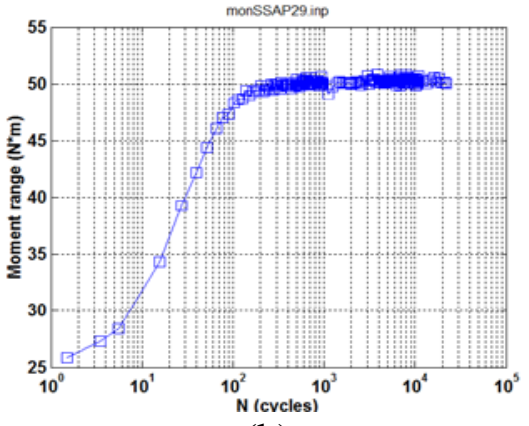

(b) 
Figure 31 Variation of (a) curvature, (b) moment, and (c) rigidity based on on-line monitoring of SSAP29: $\pm 250 \mathrm{~mm}, 2 \mathrm{~Hz}$.

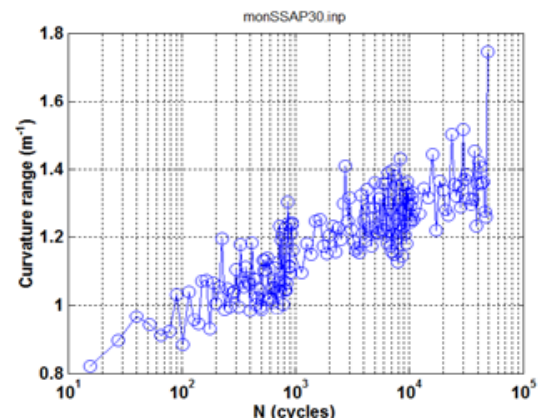

(a)

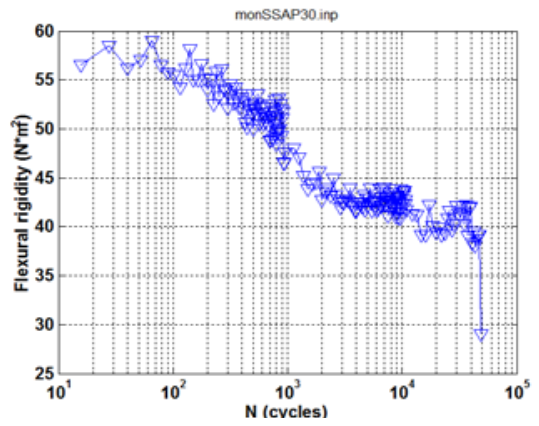

(c)

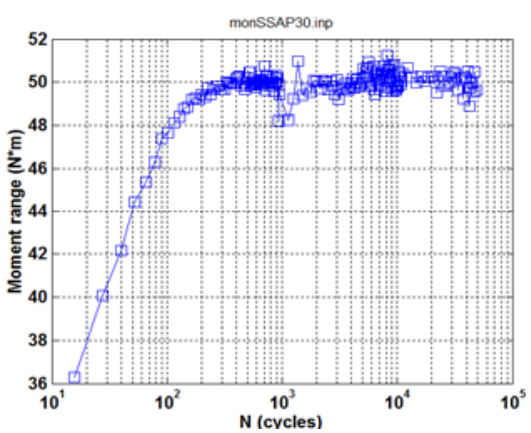

(b)

Figure 32 Variation of (a) curvature, (b) moment, and (c) rigidity based on on-line monitoring of SSAP30: $\pm 250 \mathrm{~mm}, 2 \mathrm{~Hz}$.

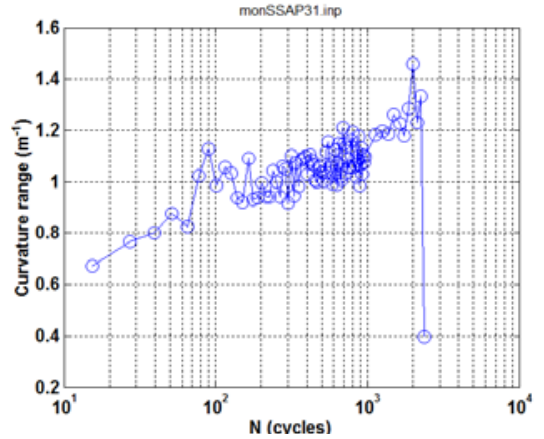

(a)

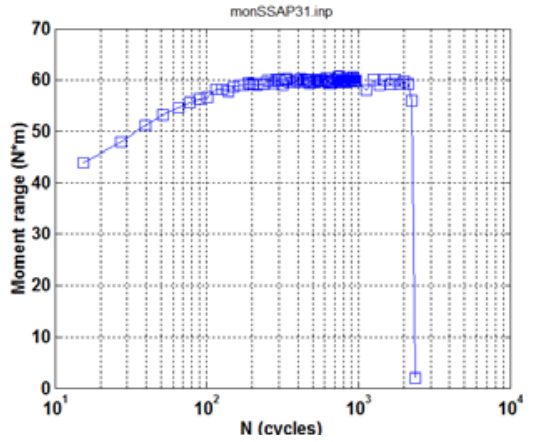

(b) 


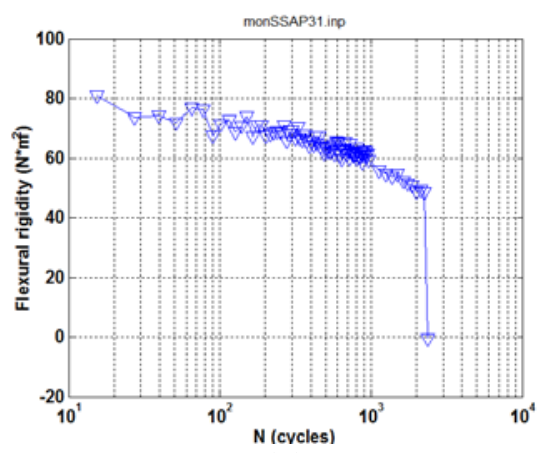

(c)

Figure 33 Variation of (a) curvature, (b) moment, and (c) rigidity based on on-line monitoring of SSAP31: $\pm 300 \mathrm{~mm}, 2 \mathrm{~Hz}$.

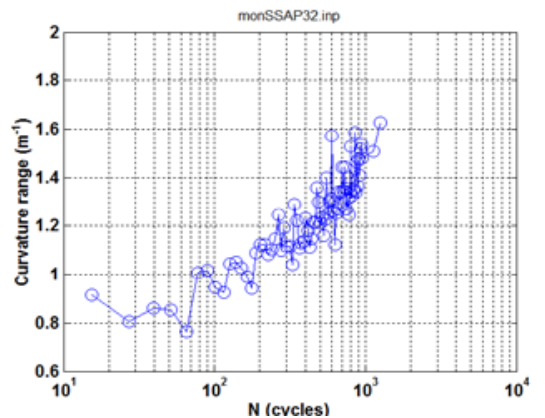

(a)

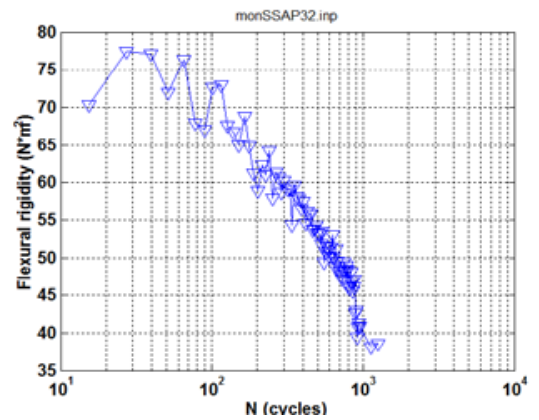

(c)

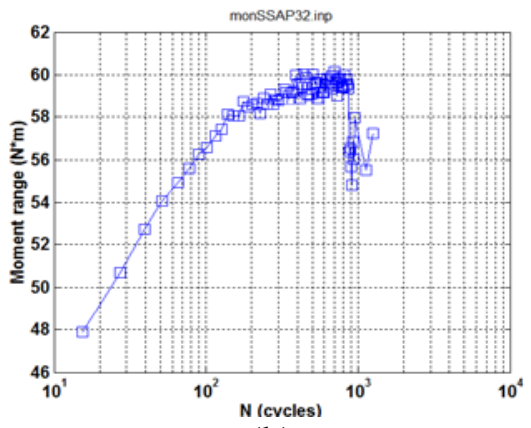

(b)

Figure 34 Variation of (a) curvature, (b) moment, and (c) rigidity based on on-line monitoring of SSAP32: $\pm 300 \mathrm{~mm}, 2 \mathrm{~Hz}$. 


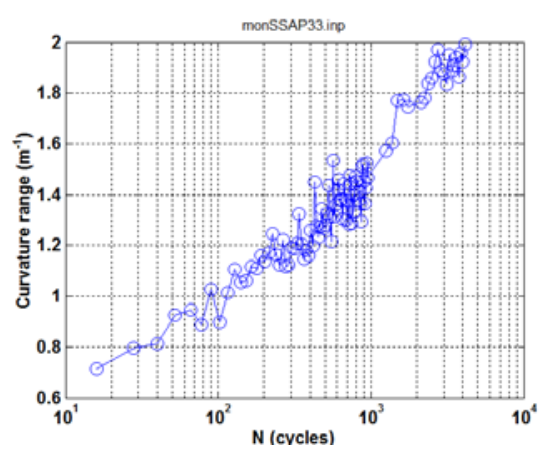

(a)

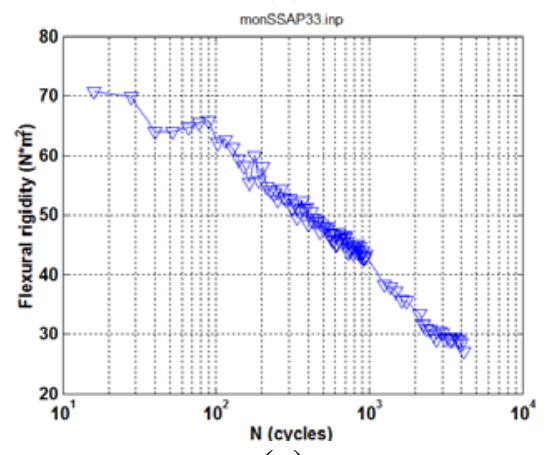

(c)

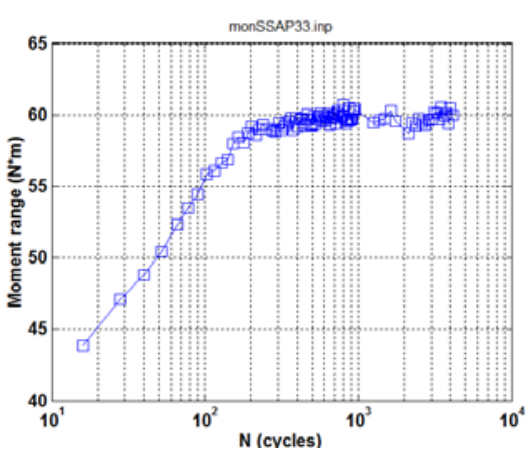

(b)

Figure 35 Variation of (a) curvature, (b) moment, and (c) rigidity based on on-line monitoring of SSAP33: $\pm 300 \mathrm{~mm}, 2 \mathrm{~Hz}$.

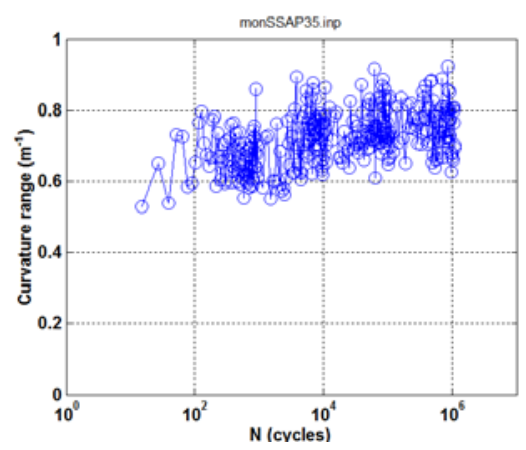

(a)

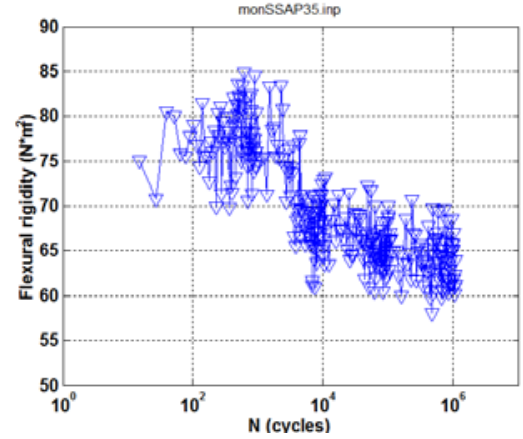

(c)

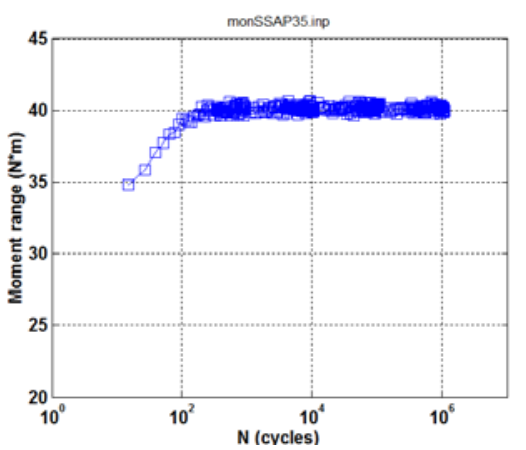

(b) 
Figure 36 Variation of (a) curvature, (b) moment, and (c) rigidity based on on-line monitoring of SSAP35: $\pm 200 \mathrm{~mm}, 2 \mathrm{~Hz}$.

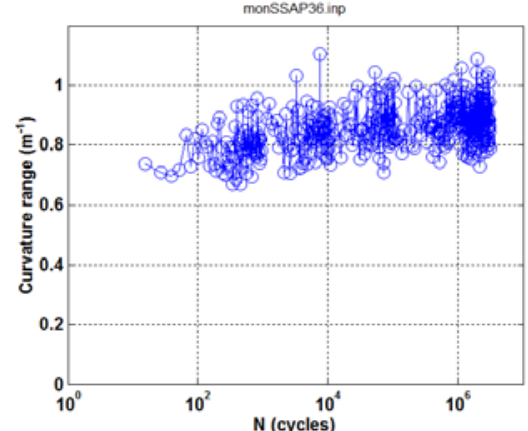

(a)

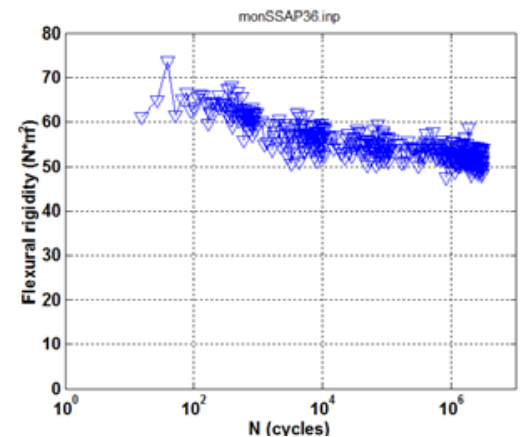

(c)

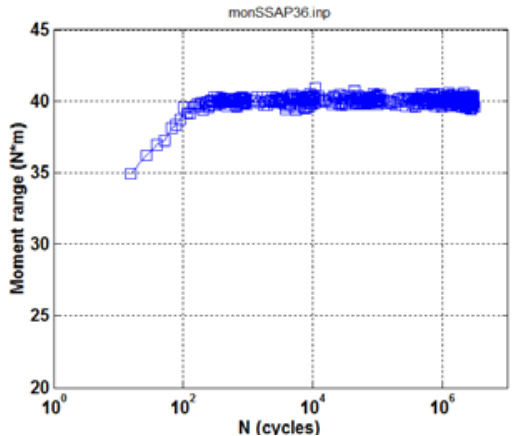

(b)

Figure 37 Variation of (a) curvature, (b) moment, and (c) rigidity based on on-line monitoring of SSAP36: $\pm 200 \mathrm{~mm}, 2 \mathrm{~Hz}$. 


\section{Cable Adaptation and Central Panel}

\subsection{Initial Communication}

A meeting in November 2012 with I\&C group occurred to discuss the integration of cables and wires into a center panel. The panel (Figure 38) will integrate the cables and wires from axial motors $1 \& 2$, displacement transducers $1 \& 2$, load cells $1 \& 2$, aux $1 \& 2$, and rod curvature measurement LVDTs 1, 2, \& 3. The integrated cable(s) from the center panel to the outside of the hot cell is being designed.

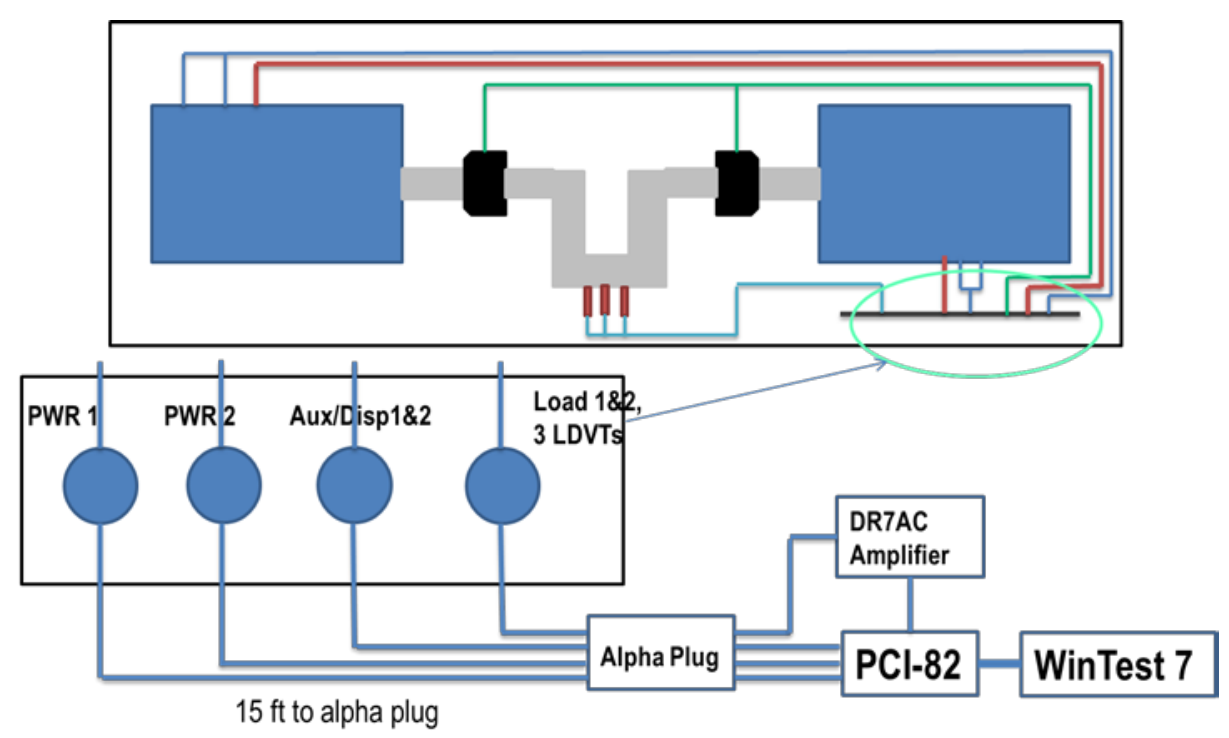

Figure 38 Concept of central panel for bending fatigue testing system

\subsection{Central Panel and Alpha Plug}

ORNL's I\&C group initiated the design and fabrication of cabling and wiring components for the Bose testing system in this reporting period (the existing cable was 6' long and a cable of at least 15 ' is needed to pass thru the hot cell alpha plug). Major highlights include: 1) design of in-cell cables. 2) Design and fabrication of the alpha plug. 3) Design and fabrication of the central panel. 3) Design and fabrication of connectors including two connectors for two power heads, one for the Bose LVDTs and auxiliaries, and one for the Bose load cells and ORNL LVDTs. The central panel and alpha plug were fabricated in February 2012, and are shown in Figure 39 and Figure 40, respectively. 


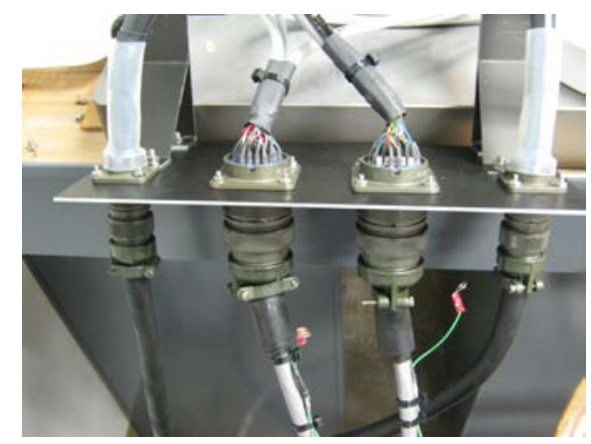

Figure 39 The initial design of central panel.

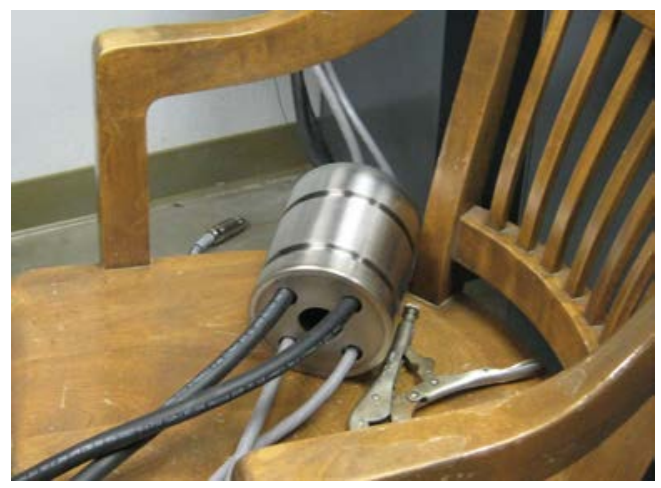

Figure 40 Alpha Plug

A number of problems were encountered in the modification of Bose cables. 1) Two fuses blew during the voltage measurement of the power cable for one of the power heads. After replacing the bad fuses, the power modular supply worked normally. 2) A displacement fault error signal appeared after the work was conducted on the in-cell cables and connectors. The problem was solved after the cable plugs were re-worked. 3) Substantial high-pitch noise came out of motor 1 when: a) system was set to run under a displacement control without a specimen installed; b) motor powers were turned on after an emergent stop; c) TuneIQ was finished under displacement control for either linear motor 1 or linear motor 2 (after WinTest 7 was restarted and motor powers were turned on).

Troubleshooting and resolution of this issue involved many communications with Bose ElectroForce Systems. The wire cross-talk was believed to be responsible for the noise observed. Several approaches have been proposed to address this issue, including replacing cables with individually shielded twisted pairs, modifying the panel, and re-organizing the cables.

The debugging on the cable noises of the testing system demonstrated that the central panel needs to be re-designed to have an improved shielding and grounding of electric connectors. A 
new central panel was fabricated in March 2012. The new panel uses a self-aligning mechanism to facilitate the assembly of the panel components in hot-cell and is shown to be easily to handle in assembling and disassembling, Figure 41.

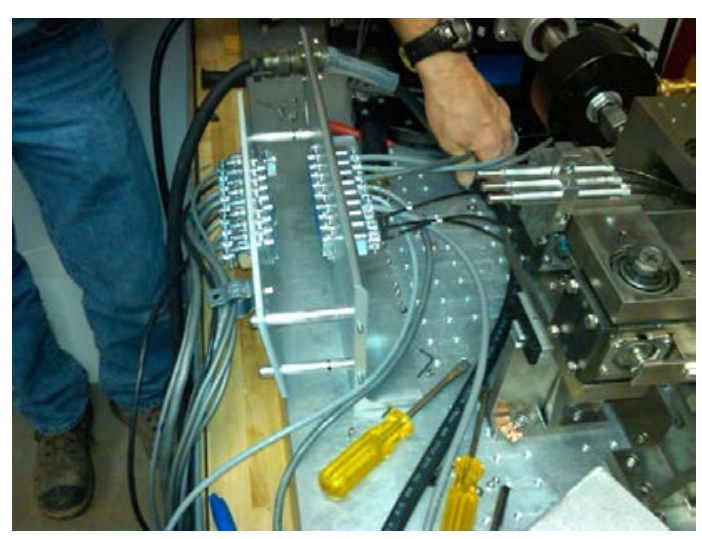

Figure 41 Re-designed central panel

Meanwhile, the following work has been carried out Bose machine in this past period:

- Move all the connectors of motor \#1 from front to back to have the more space to install the central panel.

- Replace the AUX1 connector on the circuit board with a new connector. The default signal experienced during the previous start-up process has been eliminated after the replacement of the connector.

The central panel was mounted to the edge of Bose breadboard near Axial \#1 by using two 80/20 beams as shown in Figure 42. 

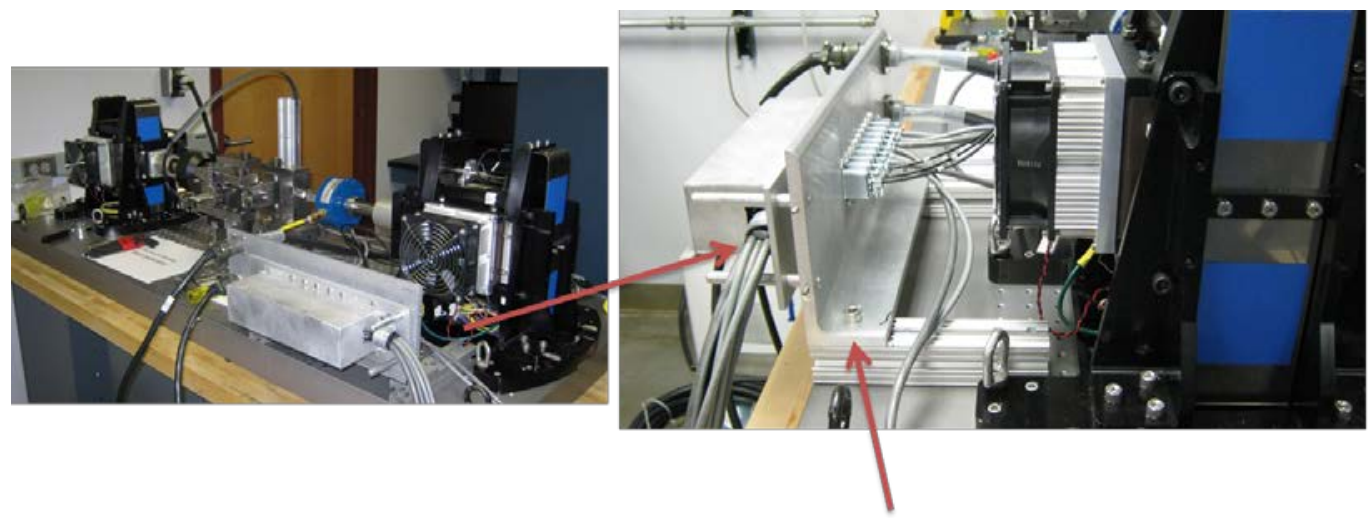

Central panel is mounted on the Bose breadboard.

Figure 42 Central panel mounted to the Bose breadboard with re-worked power cables

\subsection{Integration of RDP LVDTs}

The calibration of three RDP LVDTs (D5/200AG-337, 100M Rads, $\pm 5 \mathrm{~mm}$ ) ${ }^{9}$ for the curvature measurement of the spent fuel rod was completed by using a calibration fixture in May 2012 (Figure 43). A separate power module is used to power the RDP amplifier (DR7AC) ${ }^{10}$ because the given Bose PCI controller ${ }^{5}$ cannot provide the sufficient electric current as required.

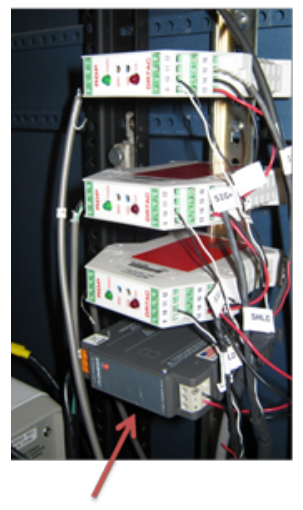

- Three LVDTs are wired into Bose controller PCl-82.

- A separate power supply is used because RDP amplifiers demand more electric current than what can be supplied by $\mathrm{PCl}-82$.

- Project file of data acquisition was modified to include three LVDTs into input channels - examination of integration of LVDTs into WinTest 7 is ongoing.
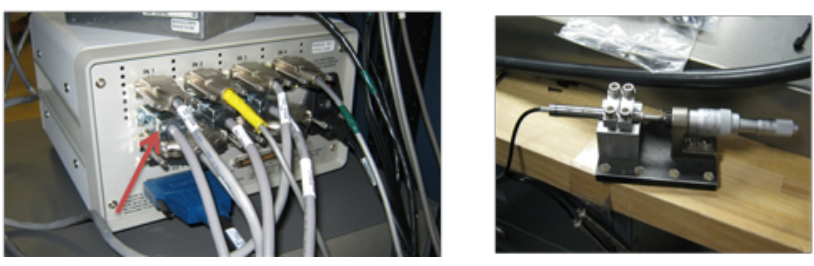

Figure 43 Calibration and integration of RDP LVDTs.

A couple of problems were encountered when incorporating the RDP LDTVs into Bose system. 
1) The mounting of three LVDTs into the sensor clamp introduced a significant amount of oscillatory noises. A substantial effort was made in debugging. The I\&C group was called, and the grounding and shielding were examined. However, the noise persisted. The wiring of the LVDT amplifiers was modified after consulting the manufacturer. After the re-wiring, the oscillatory noise has been under control to a certain extent. The evaluation on the effect of the noise is ongoing.

2) The calibration indicated that the reading of WinTest meters for RDP LVDTs didn't give a linear response to the input from calibration micrometer. The test showed that the output of RDP amplifiers (DR7AC) was responding linearly to the input. However, the both the readouts of PCI controller and the meters of Bose WinTest delivered a distorted signal (Figure 44). It is believed that there is something happening with the PCI connector and reserved PCI channels. The Bose has been requested to help us analyze the problem. The debugging at the ORNL is also ongoing.

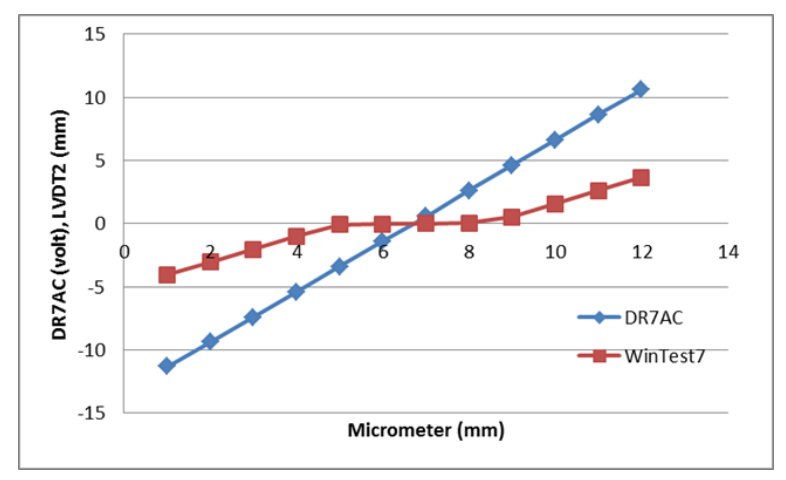

Figure 44 A nonlinear response was revealed between the target and meter reading in WinTest7.

A detailed examination showed that a 3-wire was used in the connection between DR7AC amplifier and the PCI controller. This connection is different from the 6-wire connection of Bose Disp1 to the same controller. The wiring was modified according to the ElectroForce Dual LM2 TestBench Reference Manual (2012) ${ }^{5}$ as shown in Figure 45 and the linearity was obtained accordingly. 


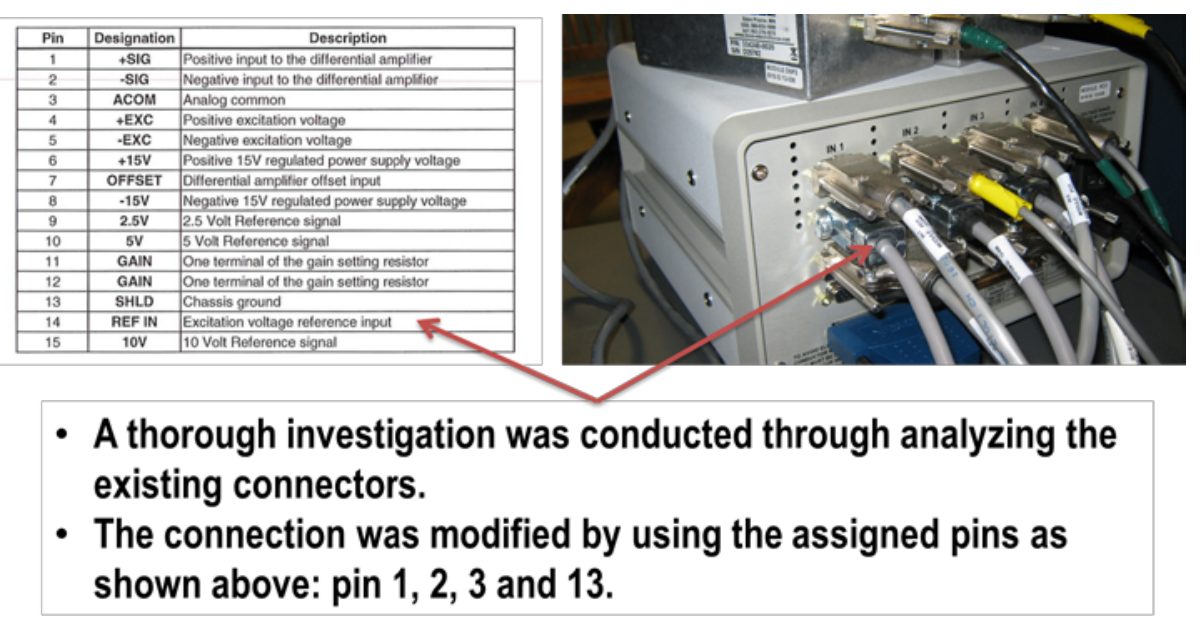

Figure 45 Linearity of RDP LVDT channels obtained after re-wired.

\subsection{Rad Hardened LVDTs for Bose TestBench}

The examination of current testing setup showed that the original shielding design of instruments in hot cell testing using lead plates is not feasible. This is because the shielding plates block the operation of manipulators.

The removal of the shielding plates will expose the transducers to the radiation from the spent fuel rod. The LVDTs and load cells in the Bose machine have to be strongly enough to withstand the radiation. It has been agreed to replace current LVDTs with a more radiation resistant ones. The MHR500 LVDTs ${ }^{11}$ for hot cell testing were ordered. The LVDTs have a $10 \mathrm{M}$ radiation resistance and will be delivered in later June 2013. Even with such radiation resistance available, the uncertainty still exists on the performance of the LVDTs. The LVDT hot-cell replacement has been studied, including double-guiding rods and a piston type. The latter was adapted and machining of LVDT parts is ongoing.

At the same time, the radiation compatibility of load cell for hot-cell testing has been studied. While the current load cells have a limited resistant capability against the direct radiation, it is suggested to consider the alternative, including the Honeywell load cell. ${ }^{12}$ The latter has a steel case material in the construction of load cell body, and would provide more reliable performance. Two $1000 \mathrm{lb}$ Model 47 type Honeywell load cells were ordered. It has an 8 weeks of delivery, and shall be shipped in later June 2013. 


\section{Summary and Future Work}

\subsection{Summary}

Work in the reported period of project has resulted in the following:

1. Bose dual LM2 TB has been calibrated. The load control mode has been implemented by using Cycle Indirect and pinning of the U-frame setup.

2. Integration of ORNL U-frame setup to the Bose TestBench has been completed through a number of modification cycles. Upgrade of U-frame setup was finished.

3. Major verification tests were completed, including cycle tests under load control, monotonic test, and load control cycle tests on MTS machine.

4. Major Bose cable modification and cable integration have been finished, including central panel and three RDP LVDTs integration.

5. Epoxy mounting procedure of rigid sleeve and test procedure have been established.

\subsection{Future Work}

1. Finish cable installation

1) Check installation to make sure there is no cross talk, no error signals, and everything powers on and operates correctly

2) The power cables with a shielding layer will be used to replace the current power cable.

2. Finish $10 \mathrm{~Hz}$ testing

3. Rad harden LVDTs for Bose machine

1) Rad hardened LVDTs are scheduled to be delivered on June 28, 2013 according to Measurement Specialties, Inc.

4. Replace load cells

1) Honeywell load cells are scheduled to be delivered on June 21, 2013.

5. Bose final check

1) Bose is being contacted for the last week of June or the first week of July. 


\section{Acknowledgments}

The authors gratefully acknowledge Rob Howard for reviewing this report; and Program Manager Michelle Flanagan and Patrick Raynaud of the Office of Nuclear Regulatory Research, U.S. Nuclear Regulatory Commission, for providing guidance and support. Authors would like to sincerely thank ORNL I\&C group and Chuck Baldwin for their great helping in cable modification and epoxy radiation study; Brian Sparks, Randy Parten and Chris Stevens of ORNL for their assistances in machining of $U$-frame setup components, preparation of surrogate rod specimens, and tensile testing of SS tube. The research was sponsored by NRC RES under DOE contract DE-AC05-00OR22725 with UT-Battelle, LLC. 


\section{References}

\footnotetext{
${ }^{1}$ Wang, J.-A. J., Wang, H., Yan, Y., Howard, R., and Bevard, B., High burn-up spent fuel vibration integrity study progress letter report (out-of-cell fatigue testing development - Task 2.1), ORNL/ TM-2010/288, Jan 2011

${ }^{2}$ Wang, J.-A. J., Wang, H., Tan, T., Jiang, H., Cox, T., Yan, Y., Progress letter report on U-frame test setup and bending fatigue test for vibration integrity study (out-of-cell fatigue testing development - Task 2.2), ORNL/TM2011/531, January, 2012

${ }^{3}$ Wang, J.-A. J., Wang, H., Cox, T., Yan, Y., Progress letter report on U-frame test setup and bending fatigue test for vibration integrity study (out-of-cell fatigue testing development - Task 2.3), ORNL/TM- 2012/417, August, 2012.

${ }^{4}$ ElectroForce Systems Group, WinTest ${ }^{\circledR 7}$ Software Reference Manual, Bose Corporation, 2012.

${ }^{5}$ ElectroForce Systems Group, ElectroForce ${ }^{\circledR}$ LM2 TestBench Test Instrument Reference Manual, Bose Corporation, 2012.

${ }^{6}$ Wang, J.-A. J., Wang, H., Bevard, B. B., Howard, R. L., and Flanagan, M. E., Spent nuclear fuel test system for bending stiffness and vibration integrity, Proc. 2013 International High-Level Radioactive Waste Management Conference, ANS, Albuquerque, New Mexico, USA, Arp 28- May 2, 2013.

${ }^{7}$ Wang, H., Wang, J.-A. J., Tan, T., Jiang, H., Cox, T. S., Howard, R. L., Bevard, B. B., and Flanagan, M. E., Development of U-frame bending system for studying the vibration integrity of spent nuclear fuel, J. of Nuclear Materials, 440, 2013, 201-213.

${ }^{8}$ AK Steel Corporation, Product Data Sheet 304/304L, www.aksteel.com.

${ }^{9}$ RDP Electronics Ltd., D5 \& D6 LVDT Displacement Transducer; RDP Transducers for high radiation environments, PR. No. RDP273, RDP Group 10/11/2008, www.rdpe.com

${ }^{10}$ RDP Electrosense, Inc., Technical Manual Transducer Amplifier Type DR7AC, Doc. Ref CD2402E, RDP Group, www.rdpe.com

${ }^{11}$ Measurement Specialties ${ }^{\text {TM }}$, MHR Series - Miniature General Purpose AC LVDT, Feb. 2013, www.measspec.com

${ }^{12}$ Sensing and Control, Model 47 Fatigue Rated Ultra Precision Universal Load Cell, May 2008, Honeywell, www.honeywell.com/sensing.
} 